Research Article

\title{
Surface Thermodynamic Gradients Associated with Gulf of Mexico Sea-Breeze Fronts
}

\author{
Loren D. White $\mathbb{D}^{1,2}$ and Michael Koziara ${ }^{3}$ \\ ${ }^{1}$ Department of Chemistry, Physics, and Atmospheric Science, Jackson State University, Jackson, MS 39217, USA \\ ${ }^{2}$ School of Natural Resources, University of Missouri, Columbia, MO 65211, USA \\ ${ }^{3}$ National Weather Service, Slidell, LA 70460, USA \\ Correspondence should be addressed to Loren D. White; loren.d.white@jsums.edu
}

Received 1 February 2018; Revised 26 June 2018; Accepted 8 August 2018; Published 26 September 2018

Academic Editor: Enrico Ferrero

Copyright ( 92018 Loren D. White and Michael Koziara. This is an open access article distributed under the Creative Commons Attribution License, which permits unrestricted use, distribution, and reproduction in any medium, provided the original work is properly cited.

\begin{abstract}
High spatial/temporal resolution mobile transects were used to examine the thermal and moisture structure of the sea-breeze front (SBF) along the Mississippi coast during August 2014 and 2015. Compared to most similar studies, conditions were much warmer and more humid. Results show a $1-2 \mathrm{~g} / \mathrm{kg}$ increase in mixing ratio across the mature $\mathrm{SBF}$ zone, and up to a $2.5^{\circ} \mathrm{C}$ temperature decrease. When SBF radar fine lines are identifiable, their position agrees very well with surface thermodynamic changes. Although temperatures were cooler at the coast, microscale offsets in location of thermal, moisture, and radiative features are noted in the vicinity of the SBF, particularly when the sea-breeze system is relatively weak or immature. At times, it seems that strong solar insolation causes the temperature to rise temporarily within the transition zone behind the kinematic SBF. These results are at variance with most other diagnostic studies. Some thermodynamic variations are noted within the marine air mass in connection to minor water bodies such as Biloxi Bay. The potential for passage of the SBF to at least temporarily increase human heat stress as described by heat index is also noted.
\end{abstract}

\section{Introduction}

The diurnally forced sea-breeze circulation is one of the earliest documented mesoscale phenomena and a dominant meteorological feature for many coastal locations. Conceptual understanding of the sea breeze as a thermally direct circulation forced by differential heating between land and sea [1] has been encapsulated in most basic meteorology textbooks through schematic diagrams that often imply a shallow density current analogous to a synoptic cold front. While many aspects of this description are well documented from both routine and research measurements [2], the existence and nature of the sea-breeze front (SBF) have typically been inferred from point measurements taken in the marine and terrestrial air masses, complemented by remotely sensed indicators of localized convergence. In a few cases, the spatial structure of the SBF has been investigated by in situ measurements from aircraft [3-6]. The validity of extrapolating these data to the surface and to the various geographic and climatological environments in which sea breezes occur has not yet been observationally shown. Detailed measurements of thermal and moisture scalars in the vicinity of the SBF are especially of relevance to interpretation relative to density current models of the seabreeze system.

Partly due to the range of sea-breeze environments worldwide, some ambiguity in nomenclature needs to be addressed. We will identify the sea breeze to be the movement of marine air inland due primarily to diurnal heating of air over the land by radiative and turbulent processes. This presumes that there should be surface-based convection (not necessarily producing cloud) over coastal land areas. It should be noted that not all coastal air mass contrasts necessarily meet these criteria. The sea-breeze front (SBF) then is the boundary or transitional zone between the marine and terrestrial air masses once the sea breeze is 
established. This transition may be described or inferred with reference to temperature, water vapor content, threedimensional wind patterns, atmospheric chemistry, or radar/lidar backscatter. The sea-breeze system or circulation encompasses a broader view of the sea breeze, SBF, associated convective systems (thunderstorms, convective clouds, thermal updrafts), upper return flow, and peripheral aspects of the larger-scale atmospheric conditions (e.g., Figure 2 of Sills et al. [7] for lake breeze), as well as the physical processes associated with the diurnal sea/land breeze cycle. A complicating factor in investigation of the SBF itself is that development of deep moist convection may produce cold pool outflow boundaries that interact with the SBF and sea breeze in complex ways $[3,8,9]$.

Since the primary descriptors of air mass character are temperature and humidity, we are specifically concerned with the scale and nature of their change across the SBF near the surface. In theory, this may be evaluated by three general strategies: (1) time-space conversion of high temporal resolution data from a surface observing site; (2) remote sensing (ground-based, airborne, or satellite); or (3) measurements from a mobile platform. Stationary time series not only require separating the signals of the SBF transition and local diurnal forcing, but also are limited by waiting for the SBF to cross the location $[10,11]$. Remote sensing can provide detailed structural information above a surface site or around an aircraft, but has more limited capabilities for describing horizontal thermodynamic patterns at/near a surface typified by varying vegetation, man-made obstructions, and terrain. A prominent focus of observational sea-breeze studies has been on boundary-layer kinematic structures determined from Doppler-derived winds [12]. Mobile measurements of thermodynamic properties have the potential to complement other strategies and data streams with essentially continuous data acquisition along horizontal transects designed for optimal sampling across the SBF. While aircraft have frequently been used for mobile measurements across SBFs, only recently have mobile surface measurements been used $[13,14]$.

The Gulf of Mexico coastline of Mississippi exhibits seabreeze conditions frequently during the warmer months [15]. In contrast to the intensively studied sea-breeze circulations of the east coast of Florida, the Mississippi coast is oriented east-west. The geographic setting of coastal lagoons or bays behind barrier islands is similar to Florida, though the interior land areas are more well drained and exposed to larger-scale continental influences. The typically weak summertime flow pattern is more similar to the northeastern Gulf of Mexico coastline (e.g., Florida "Big Bend") than the strong onshore flow of the South Texas coast. Observational and modeling studies of sea-breeze circulations in the region have been conducted previously by Lu et al. [16], Challa et al. [17], and Yerramilli et al. [18]. Primary applications have been to air quality and thunderstorm forecasting. Smith et al. [19] and Hill et al. [20] have shown that a regional maximum of lightning flash density in southeastern Mississippi is related to initiation of convection by the sea breeze.

In August of 2014 and 2015, mobile data were collected from a vehicular platform across Mississippi sea-breeze fronts. The data collected include temperature, humidity, solar radiation, and cloud photography, approximately perpendicular to the coastline in the vicinity of Gulfport. Analyzed in concert with routine in situ and remote sensing data, variations and evolution of the sea-breeze front at very high spatial resolution are documented. Comparisons are made with conceptual models, field measurements, and numerical model simulations from other locations which have typically indicated a decrease of temperature and increase of water vapor following SBF passage. In particular, we are concerned with what the scale and character of temperature and water vapor changes are at the surface SBF in relation to depiction of cloud and convergence fields by routine visible satellite imagery and National Weather Service (NWS) NEXRAD radar reflectivity. A specific effort was made to avoid segments of the sea-breeze system that were being affected by mature deep moist convection that would produce separate cold pools and surface precipitation.

The objectives of the current paper are limited to examination of the sea-breeze front in terms of scalar quantities from a limited number of available cases. We are not directly concerned with measurement of the actual seabreeze (wind), vertical structure, or numerical simulations.

\section{Methodology}

The mobile atmospheric observing system used (Figure 1) is similar to that of White [21], using an HMP45C with polyethylene filter to measure temperature and relative humidity at $10 \mathrm{~s}$ intervals. An R.M. Young 41301 Gill shield for the HMP45C provides superior ventilation during vehicle motion. No measurements were taken in rain, so that wet-bulbing effects are not a concern. The sensor is known to have a much faster response time for humidity than it does for temperature [22-24]. However, qualitative examination of data from many other uses of the system give reasonable confidence that the greater air flow and reduced thermal inertia of the shield (while mobile) in comparison to a J-Tube or U-Tube $[25,26]$ compensate sufficiently to make a $10 \mathrm{~s}$ logging interval appropriate when used for fair weather applications. Stops for traffic lights are noted from the GPS track in order to monitor potential for heating from the vehicle during insufficient aspiration. In 2015, a LiCor LI200 pyranometer was added for measurement of incoming solar radiation. Winds were not measured by the system, partly due to extensive blockage at the road level by forest and buildings. The vehicle was typically traveling near the local speed limits, which range from 30 to 65 miles per hour $(13-29 \mathrm{~m} / \mathrm{s})$.

Similar "mobile mesonet" observing systems have previously been used primarily for studies of urban heat islands and of severe convective storms. None have previously documented the sea-breeze front, though similar efforts with lake breezes have been initiated by Curry et al. [13] (in Manitoba, Canada), Brook et al. [27] (in Ontario, Canada), and Horel et al. [14] (in Utah).

In general, there are three basic ways to portray mobile mesonet data: (1) time series; (2) spatial series or cross sections; and (3) geographic map views such as that with 


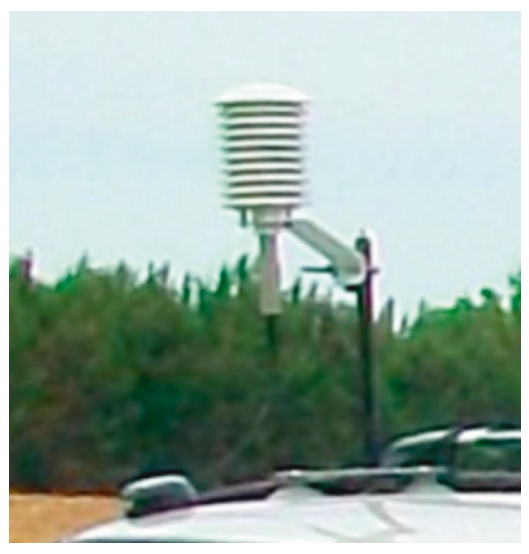

(a)

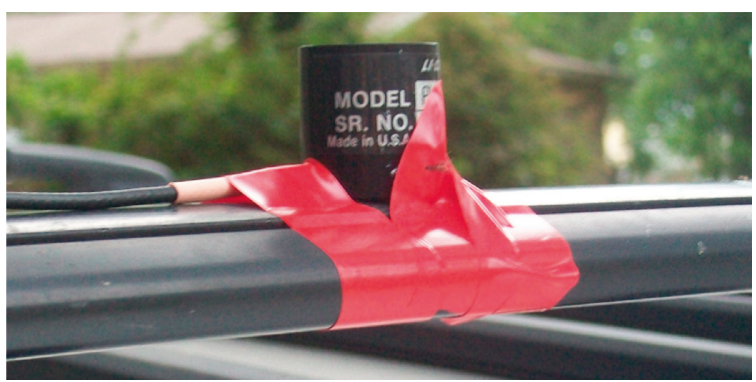

(b)

Figure 1: (a) HMP45C in Gill shield and Garmin GPS. (b) LI-200 pyranometer mounted on vehicle cross-bar.

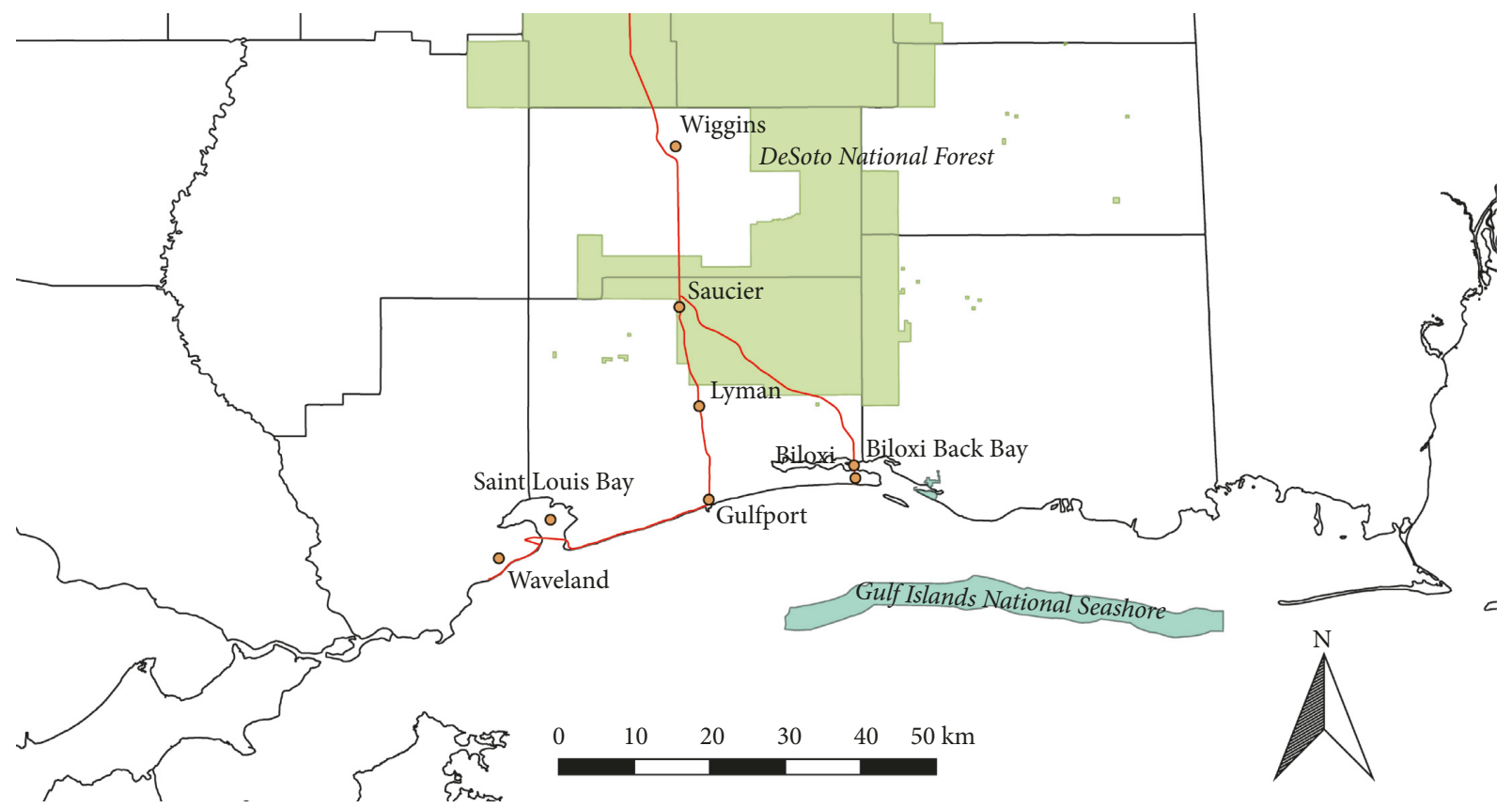

FIgURE 2: Routes and locations referred to in the text.

geographic information systems (GIS). With only surface data being collected and generally simple point-to-point routing over time segments of less than one hour each, we will emphasize spatial series versus latitude and GIS portrayal of the data. Since synoptic observations from nearby ASOS/AWOS sites did not indicate large or consistent temperature changes during any of the transects, no effort has been made to remove diurnal heating that occurred between the beginning and end of a transect. Other than basic quality control such as discarding data during and shortly after extended stops and interpolation of missing position data using a secondary GPS system, no manipulation or smoothing has been done of the raw data. However, calculation of dewpoint, potential temperature, virtual temperature, equivalent potential temperature, virtual potential temperature, and mixing ratio is done in order to improve physical interpretation. In spite of gently sloping terrain, the difference between using temperature or potential temperature could make up to a $1 \mathrm{~K}$ difference, which could be of significance to interpretation of the cross-SBF thermal gradient.

Data were obtained for synoptic and mesonet observing sites from the ASOS/AWOS, RAWS, SCAN, NDBC, and MS DMR networks in the area. Due to coarse temporal resolution and reporting precision, they are mainly of value for validating that the mobile mesonet data are reasonable and documenting the approximate local wind patterns. A useful metric of the overall thermal gradients driving the sea-breeze system is the temperature difference between PTBM6 (on Petit Bois Island) and Wiggins. The nearest in situ seasurface temperature (SST) is from buoy 42040, about $125 \mathrm{~km}$ offshore. The radiosonde site (KLIX) at Slidell, Louisiana, is 


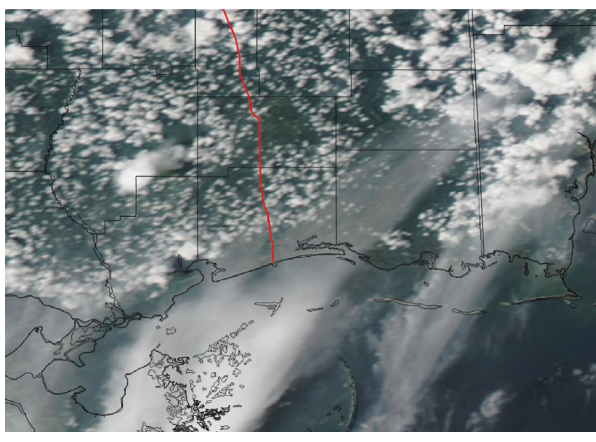

(a)

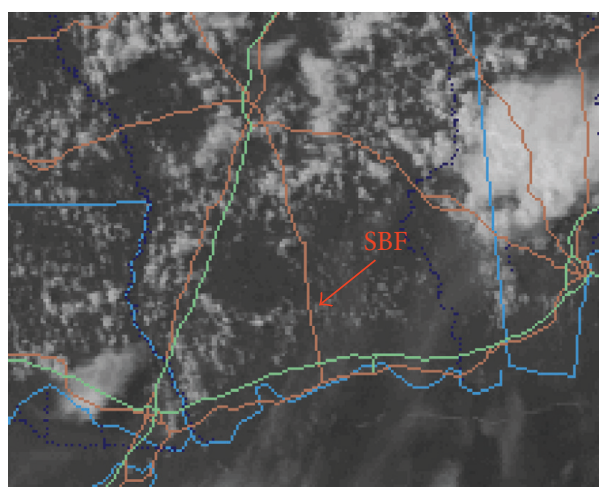

(b)

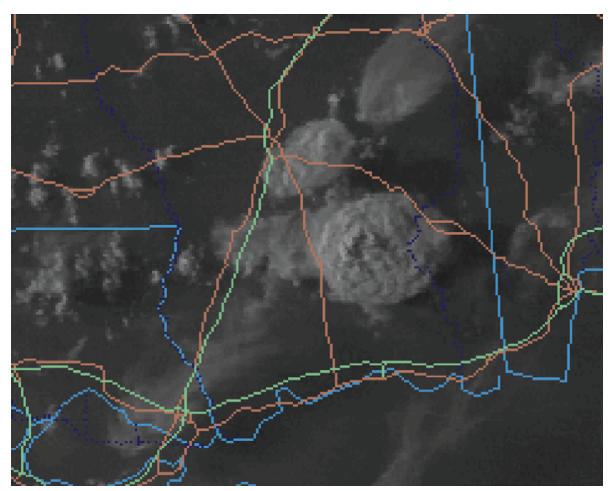

(c)

Figure 3: Visible imagery on 5 August 2014. (a) MODIS Aqua at 1835 UTC (1335 CDT). (b) GOES at time that the transect intersected the SBF (2000 UTC; 1500 CDT). (c) GOES at 2330 UTC (1830 CDT).

of limited usefulness both due to its location and the timing of launches. However, the radar data from KLIX and KMOB (at Mobile, Alabama) are both useful at times in delineating the SBF position. The association of radar reflectivity fine lines (especially in clear-air operational mode) with SBF has been noted by Simpson [28], Wilson and Schreiber [29], Wilson et al. [30], Wakimoto and Atkins [31], and Sills et al. [7]. Although some mobile data were collected farther inland, only data between the coast and $31 \mathrm{~N}$ will be considered. Limited transects were also made parallel to the coast near the shoreline. With the exception of urbanization within about $10 \mathrm{~km}$ of the coast, the domain is largely forested and gradually rises inland to an elevation of about $100 \mathrm{~m}$. Locations referred to are summarized in Figure 2.

\section{Discussion of Cases}

3.1. 5 August 2014. One southbound transect was made to Gulfport on the afternoon of 5 August 2014 between 1930 and 2025 UTC (1430-1525 Central Daylight Time/CDT). Through most of the day, anvil cirrus clouds spread northeastwards across the Mississippi coast from early convection south of New Orleans (Figure 3(a)). It seems that the development of the sea-breeze front may have weakened as the cirrus interfered with differential radiative heating. There was widespread deep moist convection within a broad area of high pressure and light winds inland. However, no precipitation was encountered by the mobile observing system. When the sea-breeze front was encountered at $30.58 \mathrm{~N}$ around 1959 UTC (1459 CDT), the most notable feature was a sudden $2 \mathrm{~g} / \mathrm{kg}$ increase of mixing ratio (Figure 4(a)). This location determined from the mobile transect data is indicated in Figures 3(b) and 4. A circular area of clearing northwest of the SBF intercept (Figure 3(b)) developed from the collapse of the small convective system seen at 1835 UTC (Figure 3(a)), but does not seem to have impacted the mobile dataset. In addition to the step increase of water vapor over less than one $\mathrm{km}$, there was much less variability of the moisture variables in the maritime air than in the convectively active terrestrial air mass, in agreement with observations of Laird et al. [32] in Florida. Radar fine lines at the lowest elevation angle of the KLIX (approximately $990 \mathrm{~m} \mathrm{AGL}$ at SBF transect crossing) and KMOB (approximately $1260 \mathrm{~m} \mathrm{AGL)} \mathrm{radars} \mathrm{(Figure} \mathrm{5)} \mathrm{were} \mathrm{iden-}$ tified independently of other data and noted to be remarkably coincident with the measured step increase of water vapor (Figure 6(a)), presumably indicating the boundary-layer convergence zone of the kinematic SBF [12]. The combination of the radars not being operated in clearair mode at the time and the beams being so high makes use of reflectivity data somewhat challenging.

In contrast to the conventional portrayal as an advancing density current [33], no drop in temperature occurred immediately south of the SBF (Figure 4(b)). Instead, there was a slight initial temperature rise of about $0.5 \mathrm{C}$, followed a couple of $\mathrm{km}$ further south by a gradual cooling trend of 


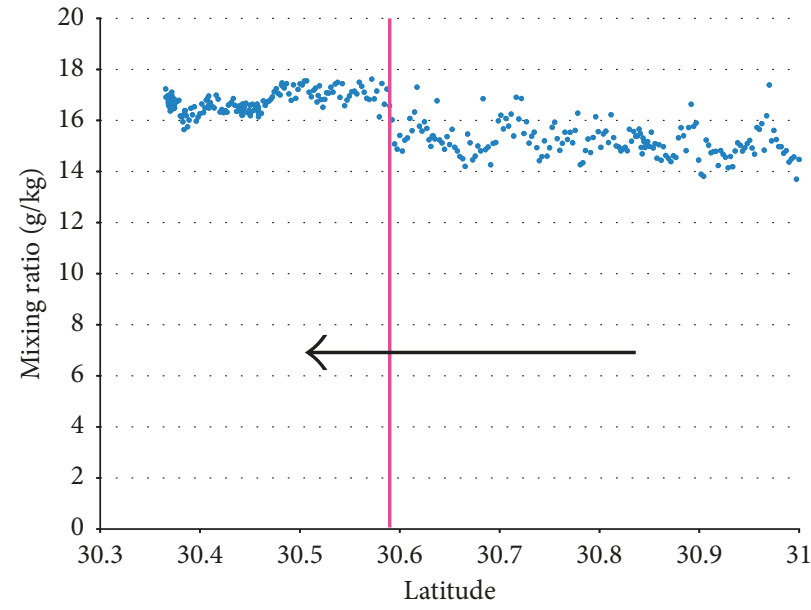

(a)

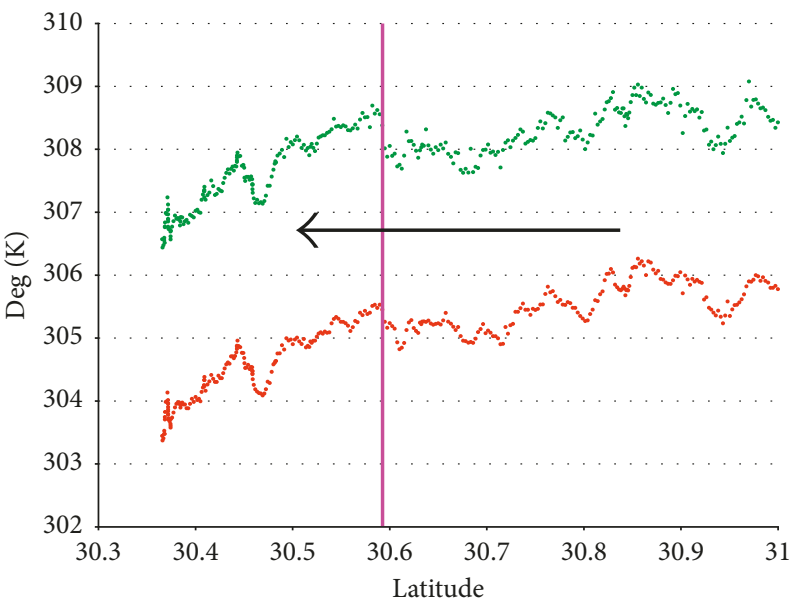

(c)

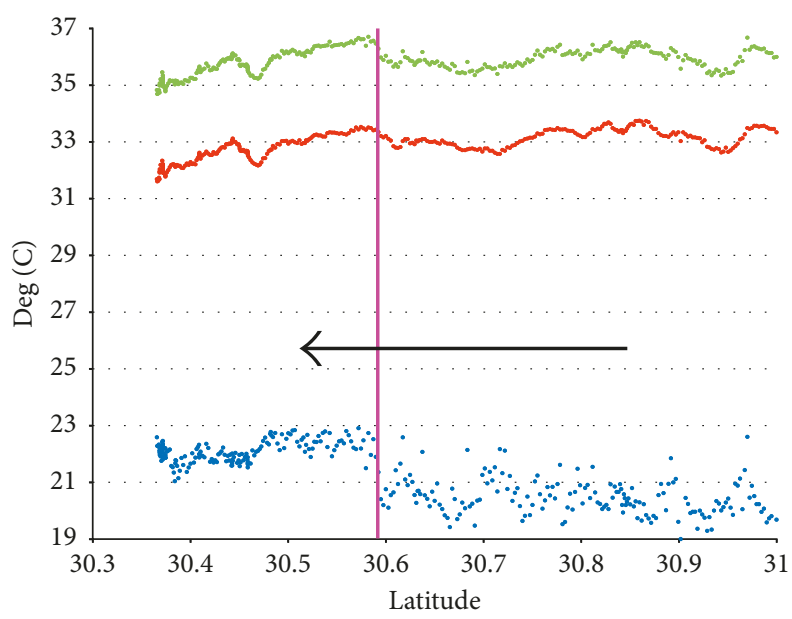

(b)

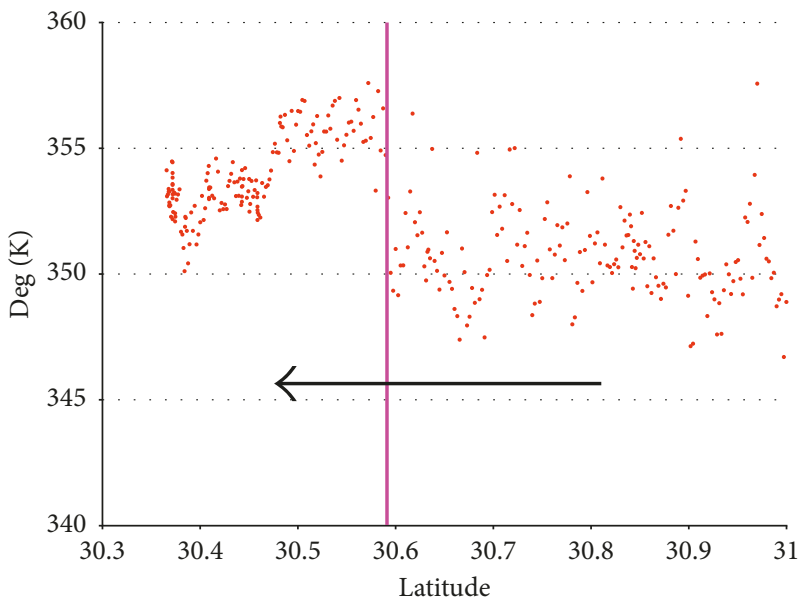

(d)

FIgURE 4: Southward transect data on 5 August 2014 plotted against latitude. Magenta line indicates position of SBF (as described in text). Arrows indicate the direction of vehicle motion. (a) Mixing ratio in $\mathrm{g} / \mathrm{kg}$. (b) Temperature (red), dewpoint (blue), and virtual temperature (green) (deg C). (c) Potential temperature (red) and virtual potential temperature (green) (K). (d) Equivalent potential temperature (K).

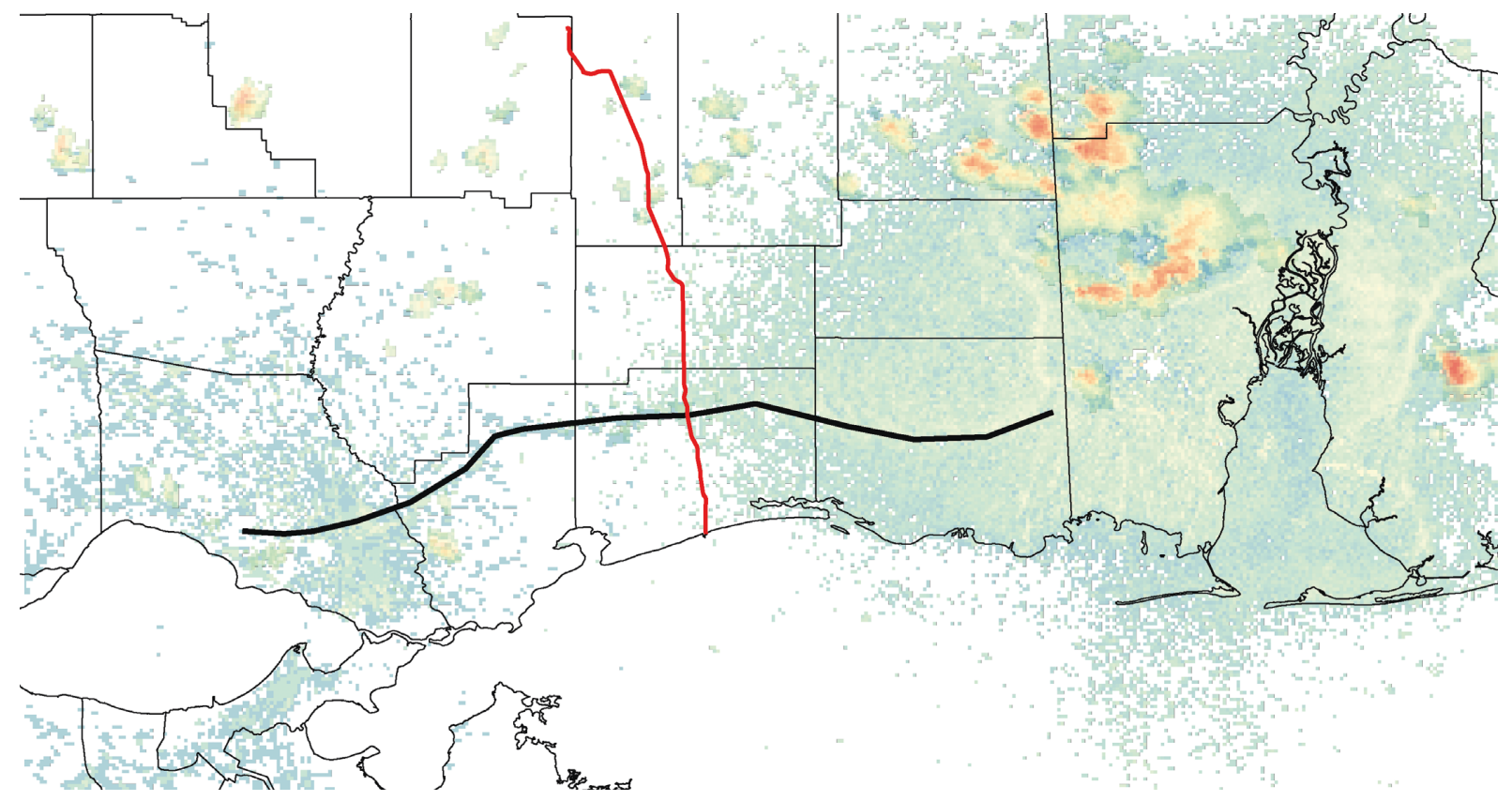

FIgUre 5: Radar reflectivity from KLIX and KMOB at 2000 UTC on 5 August 2014, with SBF fine line identified. 


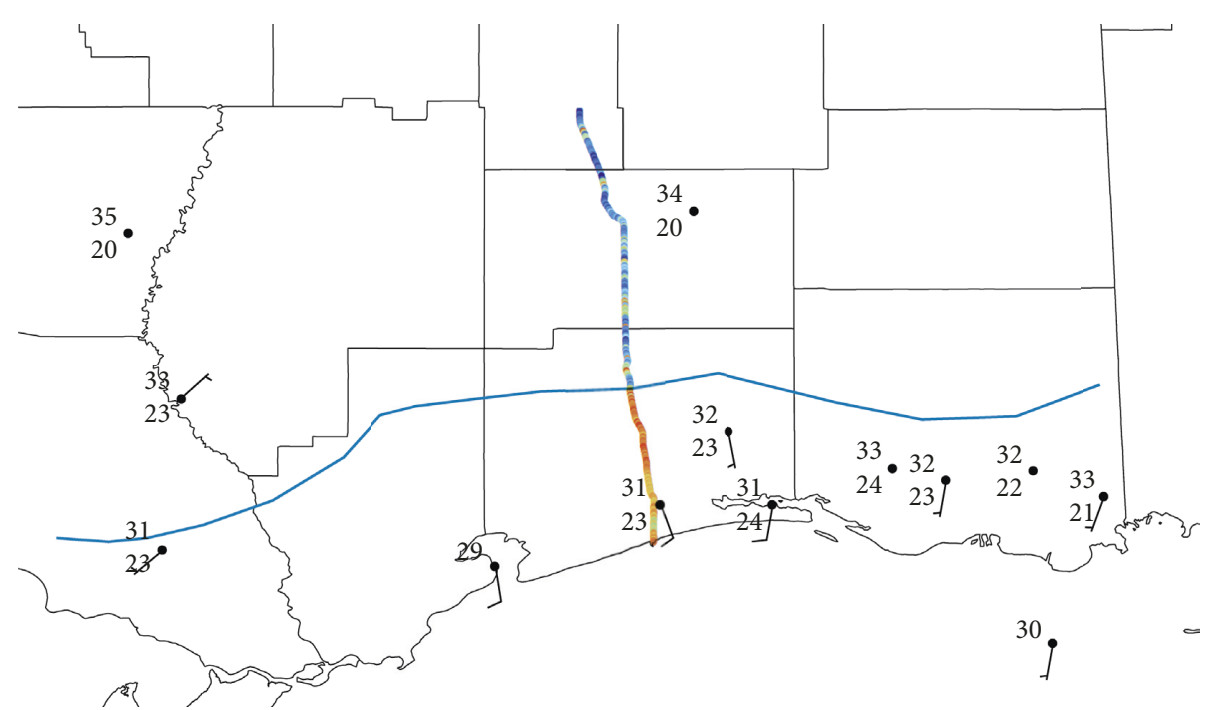

(a)

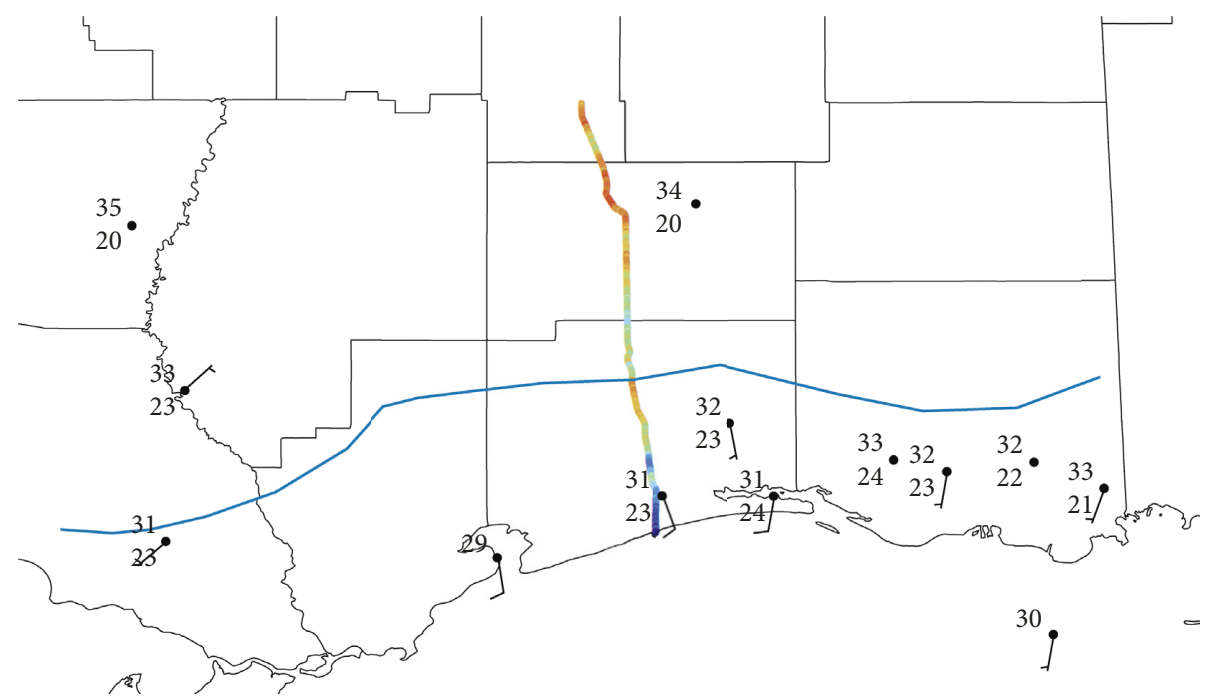

(b)

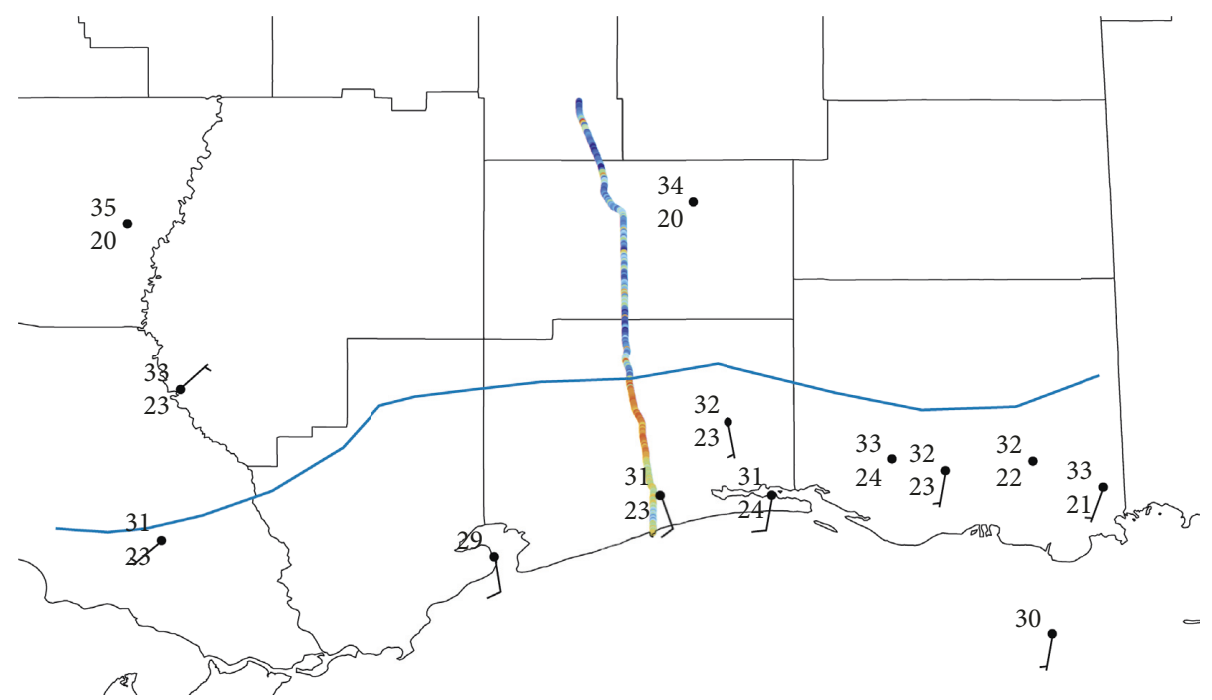

(c)

Figure 6: Map views of 5 August 2014 transect data in relation to 2000 UTC (1500 CDT) station observations. Standard station model with temperature and dewpoint in Celsius and wind speed in kt. Wind barbs are in kt. Blue line delineates position of the SBF determined from radar. All transect data are scaled with highest values in red and lowest values in blue. (a) Mixing ratio. (b) Virtual potential temperature. (c) Equivalent potential temperature. 
about $2 \mathrm{C}$ over the $25 \mathrm{~km}$ to the coast. This unconventional pattern is more evident in the patterns of virtual potential temperature $\theta_{v}$ (Figure $4(\mathrm{c})$ ) and equivalent potential temperature $\theta_{e}$ (Figure $4(\mathrm{~d})$ ), which are more directly related to parcel buoyancy effects. The detailed meteogram of Laird et al. [32] at PAM station 19 in Florida showed a somewhat similar temperature behavior in the first 20 minutes following the wind shift. Although the warm anomaly within the marine air at about $30.45 \mathrm{~N}$ could be related to intensive commercial development just north of Interstate 10 that has occurred over the previous decade, there is no local land use variation to explain warming at the SBF position. There is also no indication that traffic stops resulted in warmer temperature measurements. The most likely explanation of the step warming is that lack of convective cloud cover immediately south of the SBF increased net radiative heating to initially overwhelm cooling by advection. This could result in a microscale zone of moist surface air overriding the dry air, though there is no way to tell how persistent this feature might be.

Comparison with data from nearby hourly observing sites shows good agreement between general patterns (Figure 6). Weak southerly flow is noted south of the SBF, with light and variable winds elsewhere. The overall thermal contrast is about $4 \mathrm{C}$ between PTBM6 and Wiggins. The nearest buoy observation about $125 \mathrm{~km}$ off-shore reported a sea-surface temperature of $31.3 \mathrm{C}$. Thunderstorms were present southwest of Slidell (ASD) and northwest of Mobile (MOB). Although high-resolution wind data are not available, presumably the kinematics of the sea-breeze circulation was predominantly forced by the larger-scale mesoscale baroclinicity rather than the microscale surface variations. Later, at 2330 UTC (1830 CDT), a strong thunderstorm developed just east of the transect (Figure 3(c)), possibly in relation to interactions between the SBF and previous outflow boundaries from farther inland. This area is somewhat removed from the immediate vicinity of the transect, and the character of its sea breeze is significantly impacted by the more complex coastline shape of Mobile Bay. Inadequate surface and radar data are available to definitively link the SBF to the deep convection.

Following the collection of data southbound to the coast, data were also collected westward in close proximity to the shoreline from Gulfport to Waveland within the marine air between 2025 and 2111 UTC (1525 and 1611 CDT). Mixing ratio varied between 17 and $19 \mathrm{~g} / \mathrm{kg}$, with largest values to the west of Saint Louis Bay. Temperature was highest at the eastern end in the more heavily developed areas around Gulfport. Potential factors could be the transition to predominantly salt marsh shoreline just to the west of Bay St Louis and advective fetch from South Louisiana wetlands to the south. The wind direction of $170^{\circ}$ corresponds approximately to a line from Bay St. Louis to the easternmost mouth of the Mississippi River, so that air to the east would pass largely over open relatively deep water and that to the west over extensive tidal marshes and shallow water. It is hypothesized that contributions from evapotranspiration and a larger diurnal cycle in very shallow waters could locally increase latent heat fluxes [34], so that more water vapor might be present west of Bay St. Louis.
3.2. 6 August 2014. A more robust sea-breeze system was sampled on 6 August 2014 from south to north along the same route as the previous day between 1820 and 1918 UTC (1320 and 1418 CDT). While the coastal temperature gradient and synoptic flow pattern were very similar to the previous day, there was no widespread cirrus influence on the SBF. The average transect temperature was about $0.6 \mathrm{C}$ higher, the PTBM6-Wiggins temperature difference was again $4 \mathrm{C}$, and offshore SST was $32.2 \mathrm{C}$. The SBF was only about $10 \mathrm{~km}$ from the coast when intercepted at 1838 UTC (1338 CDT) and easily identified in visible satellite imagery (Figure 7), as well as radar reflectivity (Figure 8). Near-shore surface winds had slightly more of a southwesterly component. Unlike the previous day's case, the $2 \mathrm{~g} / \mathrm{kg}$ step increase seaward of mixing ratio coincides with decreasing potential temperature and virtual potential temperature (Figure 9). However, the drop of $\theta_{v}$ occurs more broadly over a series of steps between the coastline and a couple of $\mathrm{km}$ north of the SBF. This does not seem to be an artifact of slower thermal response of the sensor since the temperature was already changing substantially within the sea-breeze air while the mixing ratio was fairly constant. Radar data (Figure 8) again seem to indicate that the kinematic SBF was more closely collocated with variations in the water vapor field instead of temperature (Figure 10).

3.3. 10 August 2015. In August 2015, multiple passes were made through the coastal zone during one day, in order to document development and movement of an SBF in response to diurnal forcing. The six north-south transects are summarized in Table 1. Incoming solar radiation measurements were made to complement satellite documentation of cloud cover. At sunrise (1120 UTC; 0620 CDT), the area was mostly clear and typified by cooler conditions inland (Figures 11(a) and 12(a)). Dewpoints were relatively invariant initially, presumably due to widespread wet soils from a weak tropical disturbance that dissipated about $24 \mathrm{hr}$ previously. The dominant wind direction was from the southeast throughout the day. In spite of significant differential heating, a well-defined sea-breeze circulation did not advance inland during the day, no radar fine line was noted (except to the west of LIX around coastal Lake Pontchartrain), and no deep moist convection was initiated nearby. However, a strengthening air mass contrast (of temperature and dewpoint) and difference in cloud patterns (cumulus inland vs. mostly clear offshore) (Figure 11) were documented in close vicinity to the coast, which could reasonably be interpreted as a "passive" or "nonprogressive" sea-breeze pattern.

The description as "passive" is chosen in analogy with the synoptic-scale nomenclature of Djuric [35] in which a "passive cold front" is typified by a shallow density current that is not associated with deep moist convection (such as is common in segments far removed from low pressure centers and with arctic air masses). Similar to the synoptic concept of a stationary front, "nonprogressive" does not necessarily indicate that there is absolutely no motion or that the feature 


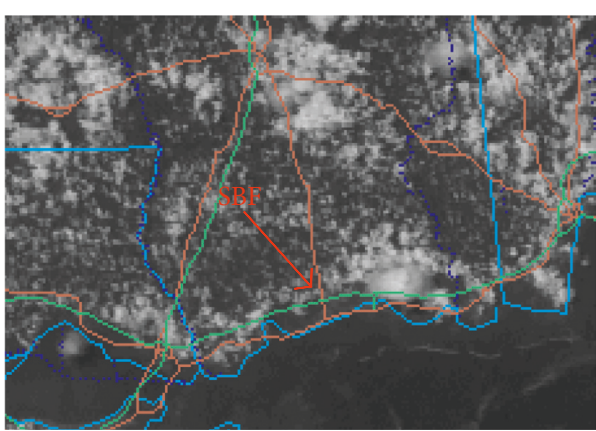

(a)

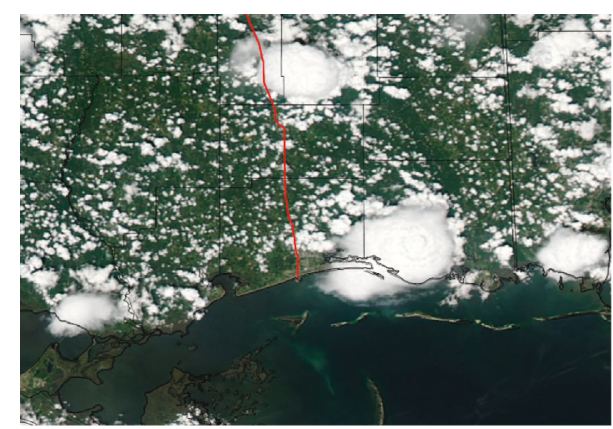

(b)

FIgURE 7: Visible imagery on 6 August 2014. (a) GOES near time of SBF intercept (1830 UTC; 1330 CDT) and (b) MODIS Aqua at 1915 UTC (1415 CDT).

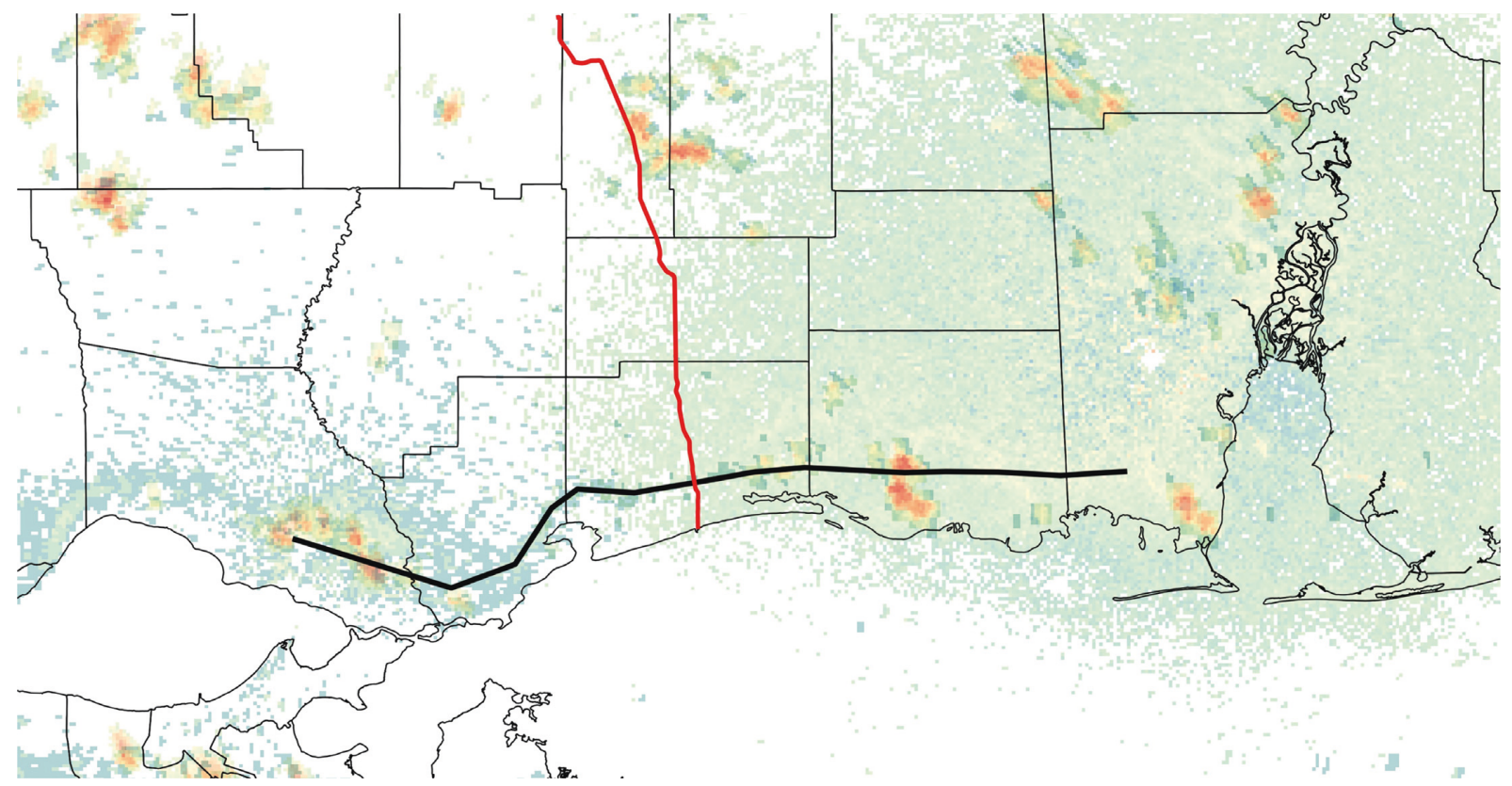

Figure 8: Radar reflectivity from KLIX and KMOB at 1840 UTC on 6 August 2014, with SBF fine line identified.

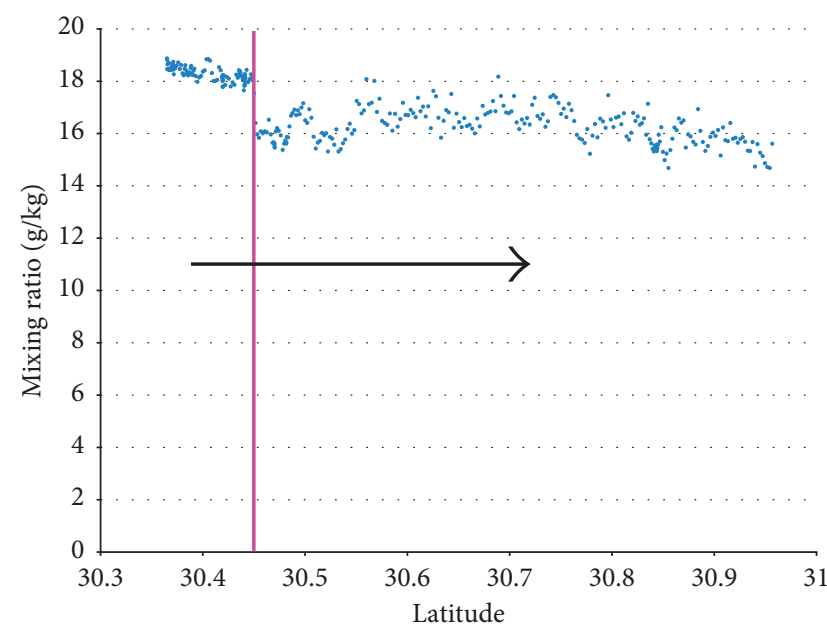

(a)

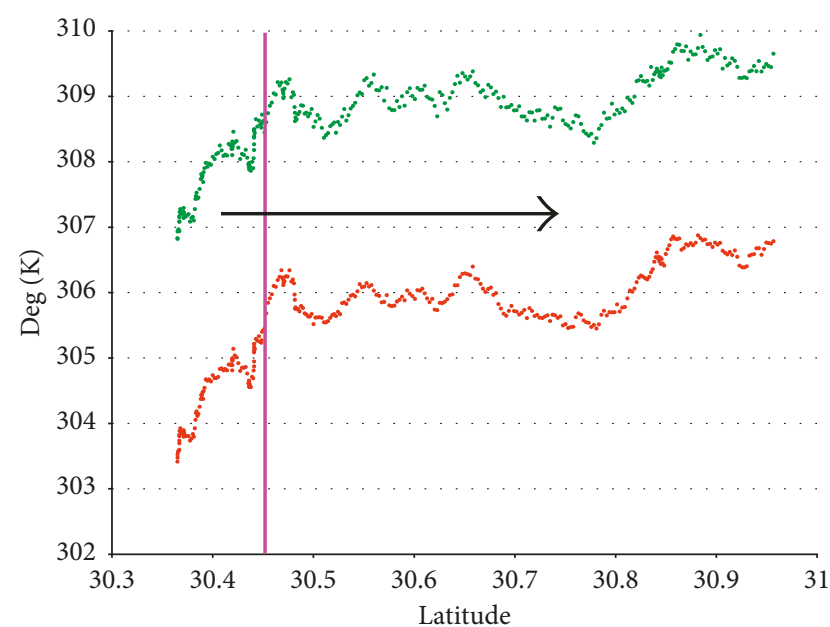

(b)

Figure 9: Space series versus latitude on 6 August 2014. (a) Mixing ratio (g/kg) and (b) potential temperature (red) and virtual potential temperature (green) (K). 


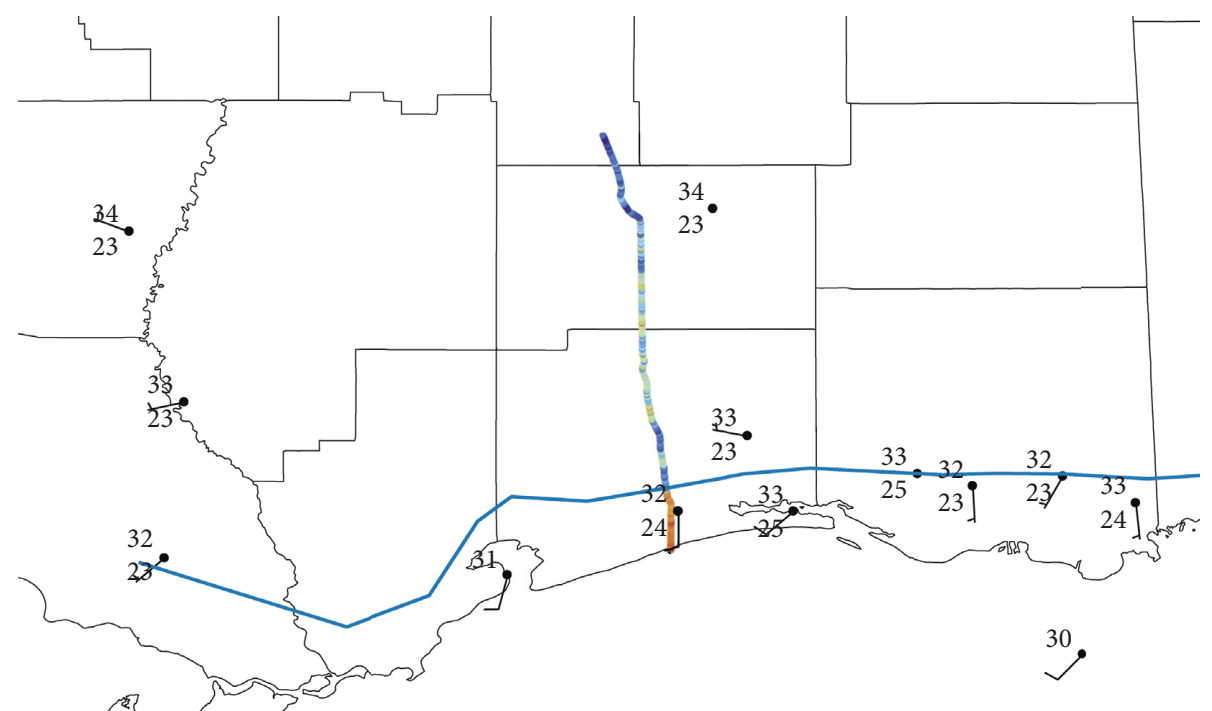

(a)

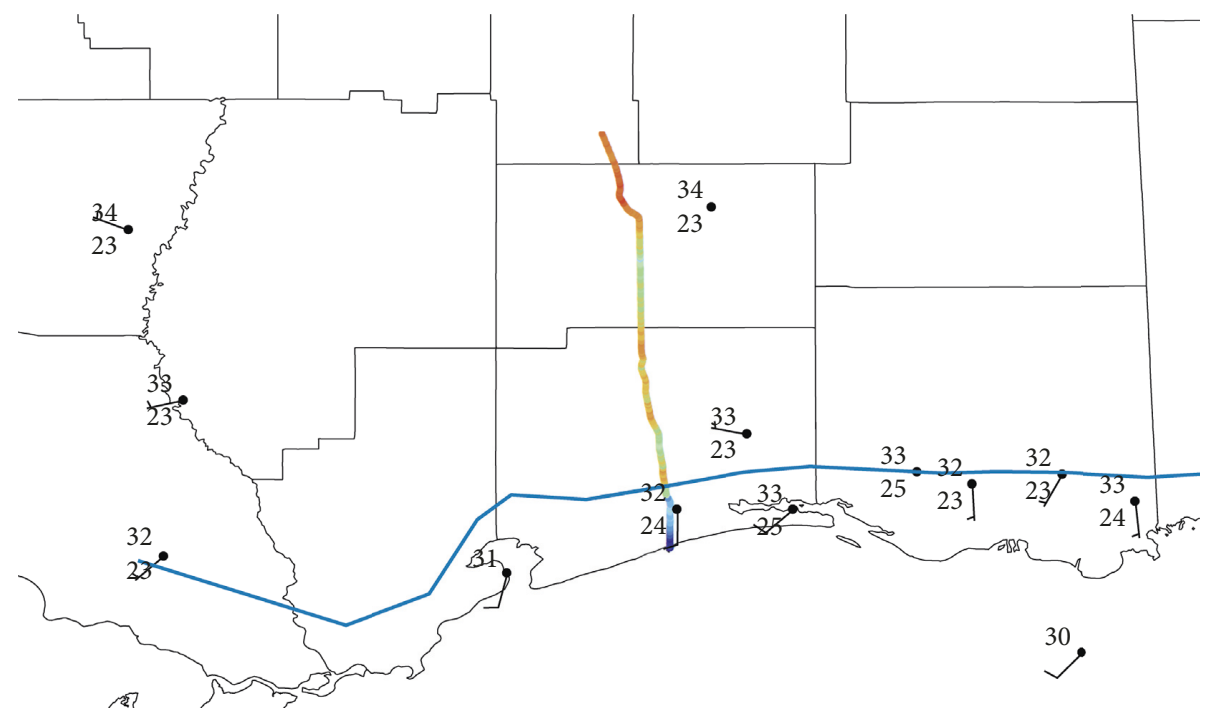

(b)

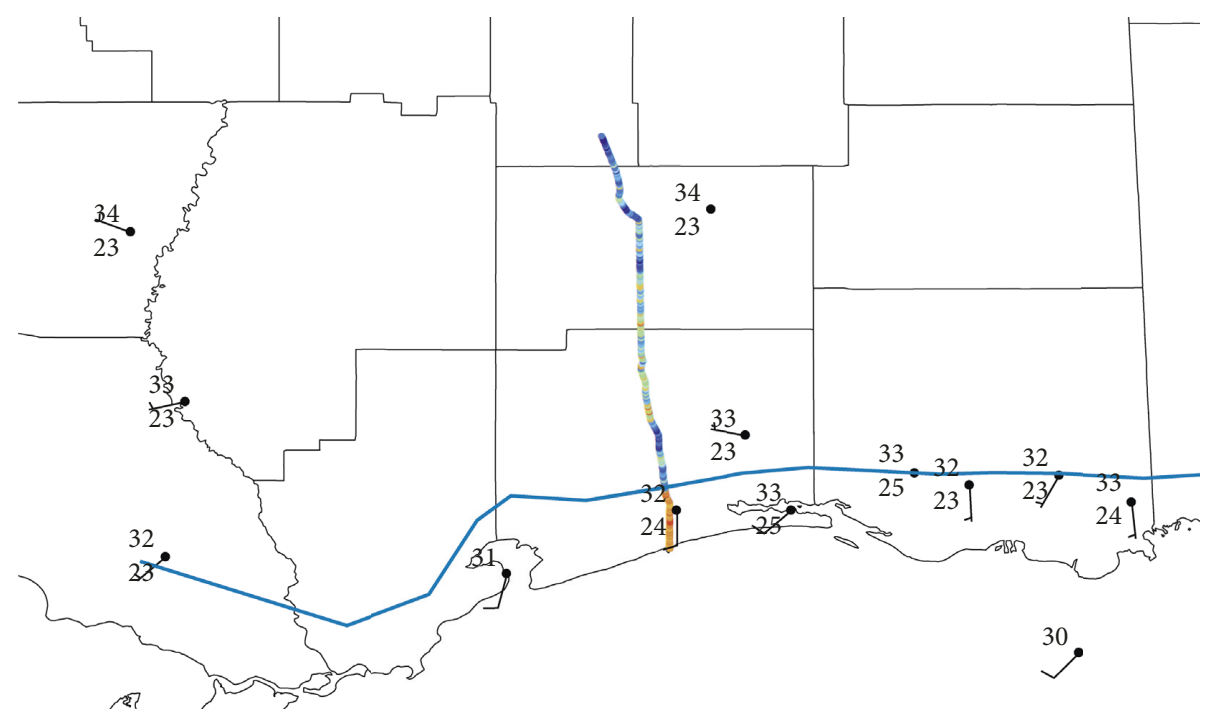

(c)

FIGURE 10: Map views of 6 August 2014 transect data in relation to temporally interpolated 1830 UTC (1330 CDT) station observations and position of the SBF from radar data. (a) Mixing ratio. (b) Virtual potential temperature. (c) Equivalent potential temperature (station model as in Figure 6). 
TABle 1: North-south transects on 10 August 2015.

\begin{tabular}{|c|c|c|c|c|}
\hline & Begin time (UTC) & SBF time & SBF latitude & End time \\
\hline Wiggins-Gulfport & 1435 & 1518 & 30.42 & 1527 \\
\hline Gulfport-Saucier & 1617 & 1626 & 30.41 & 1651 \\
\hline Saucier-Biloxi & 1651 & $1713 ?$ & 30.43 & 1717 \\
\hline Biloxi-Saucier & 1805 & $1813 ?$ & 30.47 & 1833 \\
\hline Saucier-Gulfport & 1833 & 1858 & 30.41 & 1908 \\
\hline Gulfport-Lyman & 1922 & $?$ & $?$ & 1951 \\
\hline
\end{tabular}

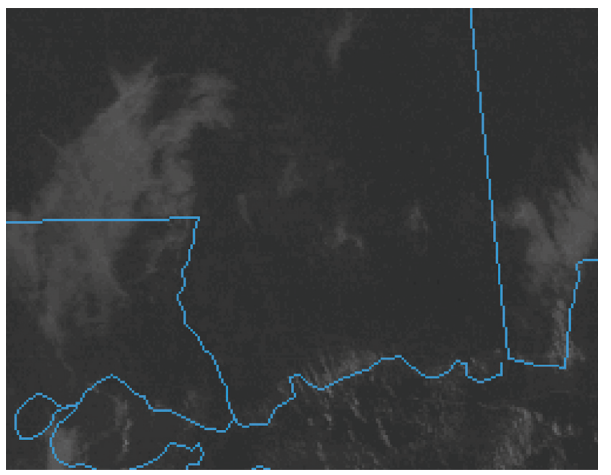

(a)

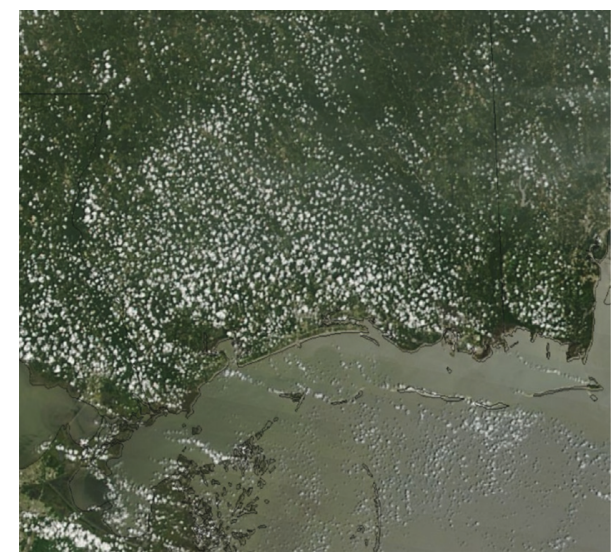

(b)

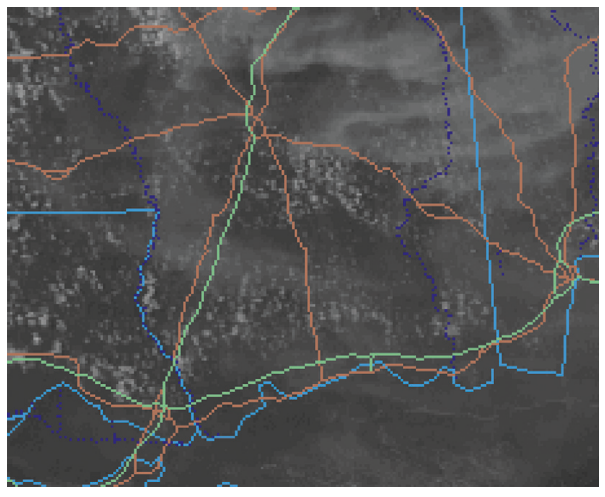

(c)

Figure 11: Visible imagery on 10 August 2015. (a) GOES at 1315 UTC (0815 CDT). (b) MODIS Terra at 1650 UTC (1150 CDT). (c) GOES at 1945 UTC (1445 CDT).

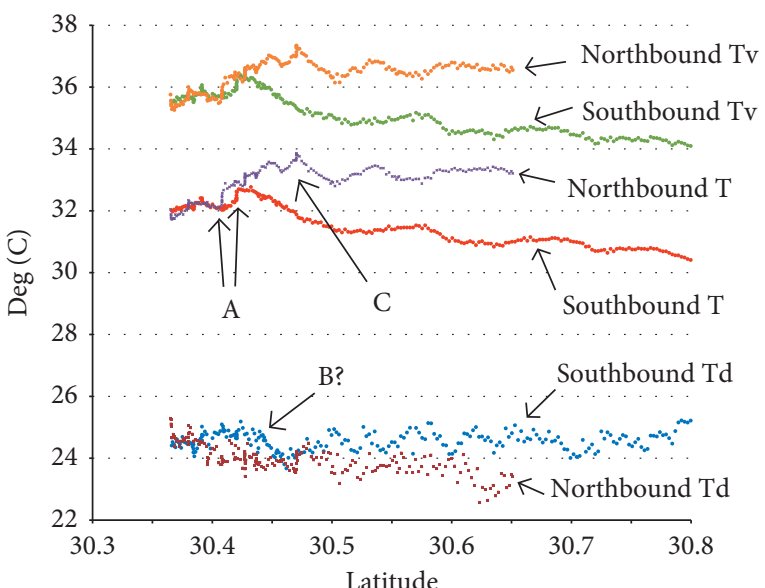

(a)

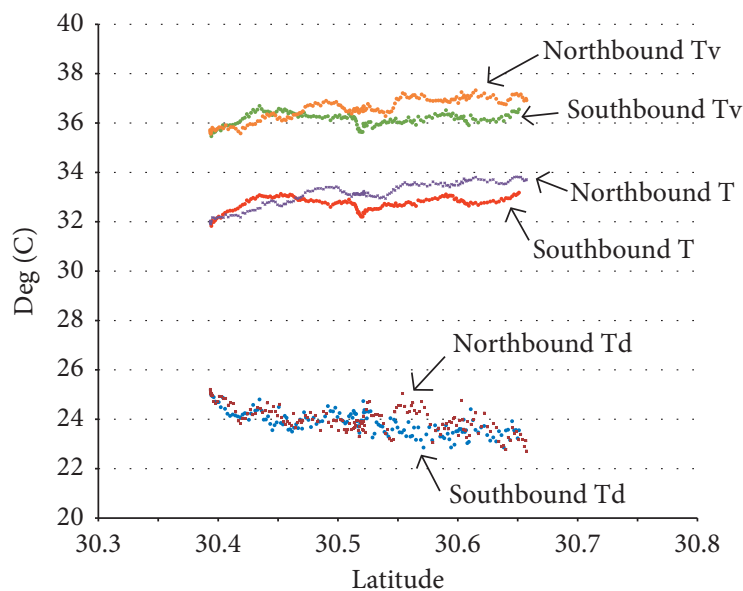

(b)

Figure 12: Continued. 


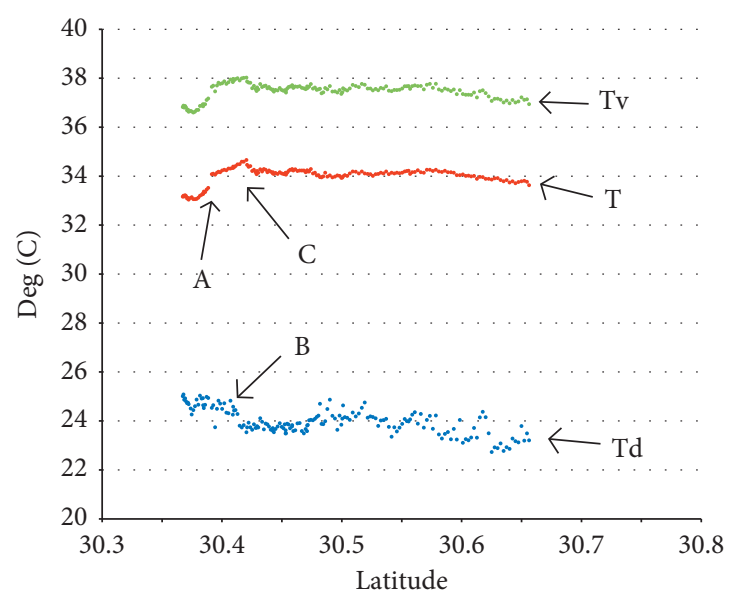

(c)

Figure 12: Space series of temperature, virtual temperature, and dewpoint (deg C) from 10 August 2015. Features are labeled as described in text. (a) Southbound Wiggins-Gulfport from 1435 to 1527 UTC (0935-1027 CDT); northbound Gulfport-Saucier from 1617 to 1651 UTC (1117-1151 CDT). (b) Southbound Saucier-Biloxi from 1651 to 1717 UTC (1151-1217 CDT); northbound Biloxi-Saucier from 1805 to 1833 UTC (1305-1333 CDT), (c) Southbound Saucier-Gulfport from 1833 to 1908 UTC (1333-1408 CDT).

is ill-defined. However, it does connote the failure to progress significantly inland as would normally be expected for an SBF. Retrogression back toward the sea would be expected during the nocturnal land breeze phase instead of during the middle of the day as documented here; however, similar motion has been noted under opposing flow by Alpert et al. [36] and Alpert and Rabinovitch-Hadar [37] in Israel. In other regions, a sea-breeze (diurnal) air mass contrast may be held nearly stationary when restricted by steep coastal terrain [38]. It may be that southeasterly synoptic flow was too strong east of LIX for typical sea-breeze development. Regardless whether one considers the observed conditions to truly constitute an $\mathrm{SBF}$, they at least represent some form of convective internal boundary interacting with the coastal environment.

During the initial southbound transect centered around 1500 UTC (1000 CDT), there was little if any direct thermodynamic evidence of a developing SBF. However, development of shallow cumulus was widespread north of a small but sudden seaward drop in temperature at $30.42 \mathrm{~N}$ (denoted "A" in Figure 12). Collecting data northward about an hour later, a very similar temperature pattern is noted at a slightly more southerly position (in spite of generally onshore winds). At this time (around 1630 UTC; 1130 CDT), diurnal heating of the land area has effectively reversed the general temperature gradient between the coast and Saucier, so that $\theta_{v}$ increases nearly $2 \mathrm{C}$ northward to about $30.47 \mathrm{~N}$ and then remains approximately constant (Figure 13). Increasing thermal contrast was also found between the southbound and return transects from Saucier to Biloxi, with temperature decreasing (increasing) over time south (north) of $30.47 \mathrm{~N}$. However, it is difficult to identify any specific location of sudden air mass change within the broad gradient (especially for water vapor) until around 1900 UTC (1400 CDT) at Gulfport, when the PTBM6Wiggins temperature difference was $4 \mathrm{C}$ and offshore SST was 31.6 C. Comparing the location of feature $\mathbf{A}$, it moved seaward by $1.2 \mathrm{~km}$ between 1517 and 1626 UTC (1017 and
1126 CDT) and $2.1 \mathrm{~km}$ more seaward between 1626 and 1901 UTC (1126 and $1401 \mathrm{CDT})$. Its location at 1901 was only $3 \mathrm{~km}$ from the shoreline. It is hypothesized that this southward propagation is indicative that the surface diurnal radiative forcing was dominant over advection in the local heat budget. Unfortunately, no radiative or turbulent flux measurements are available in suitable locations to directly determine diabatic heating contributions in this area. On the southward transect from Saucier to Gulfport, the mixing ratio rapidly increased at $\mathbf{B}$ by more than $1 \mathrm{~g} / \mathrm{kg}$ at about $30.41 \mathrm{~N}$, about $5 \mathrm{~km}$ north of the coast. Solar radiation data (Figure 14(c)) show that clouds were confined to north of $30.44 \mathrm{~N}$, approximately in the same location as a warm anomaly $\mathbf{C}$ at the north edge of the broader baroclinic zone. Although no deep cumulus convection developed, the contrasting cloud regimes are demonstrated photographically by Figure 15 . The relation of the mobile data to regional patterns is shown in Figure 16.

A conceptual summary schematic of detailed thermodynamic features associated with the passive SBF on this day is shown in Figure 17. Due to the east/west coastal orientation and position north of the Tropic of Cancer, the midday sun will be able to reach the surface a short distance inland from the overhead cumulus position. To an Eulerian observer located several $\mathrm{km}$ inland, the interpreted progression of such features moving northward would be that the first indication of the sea breeze is a slight warming due to decreased cumulus coverage (C), followed by the onset of advective cooling. Radiative heating may be sufficient to cancel out the advective cooling, while turbulent mixing processes in the vicinity of the SBF seem to temporarily delay the arrival of increased water vapor at the surface. The mixing ratio increases suddenly (B) to values representative of the marine air before leveling off, while the temperature continues to gradually decrease until a relatively sudden drop off (A) to more uniform marine conditions. It could be speculated however that the change at $(\mathrm{A})$ may be more 


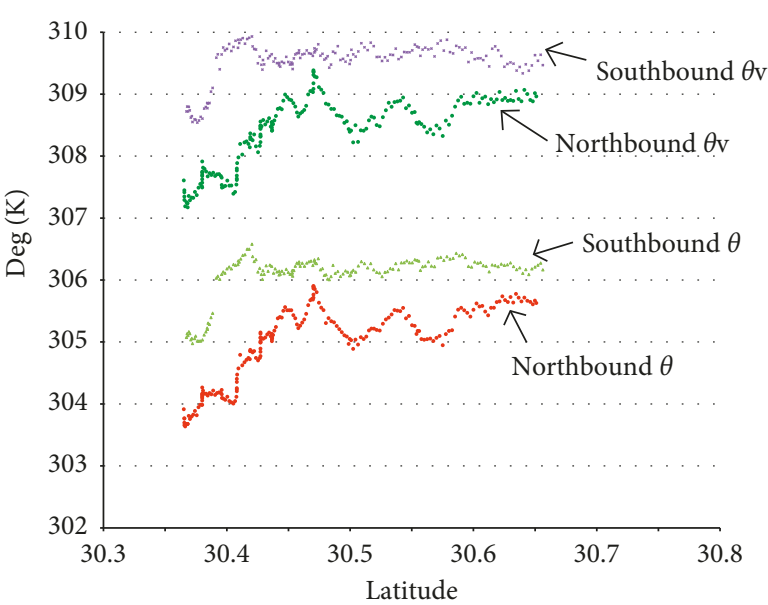

(a)

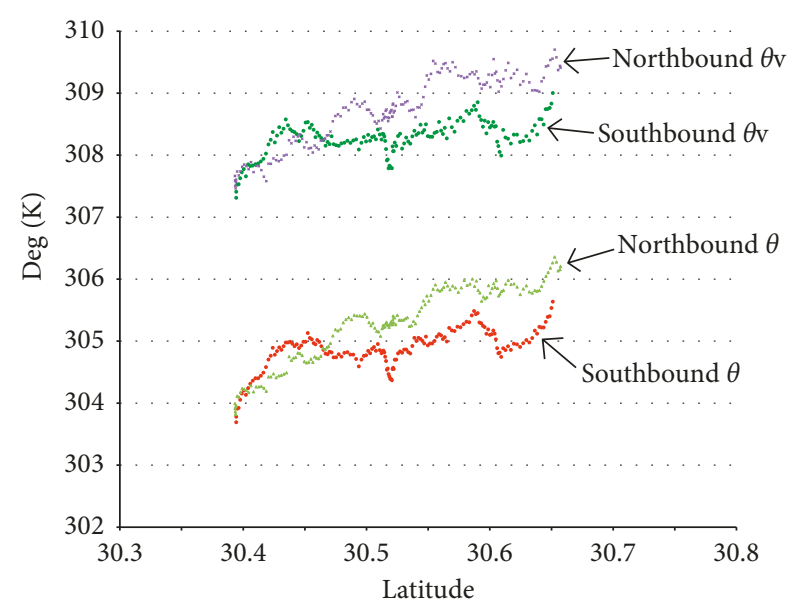

(b)

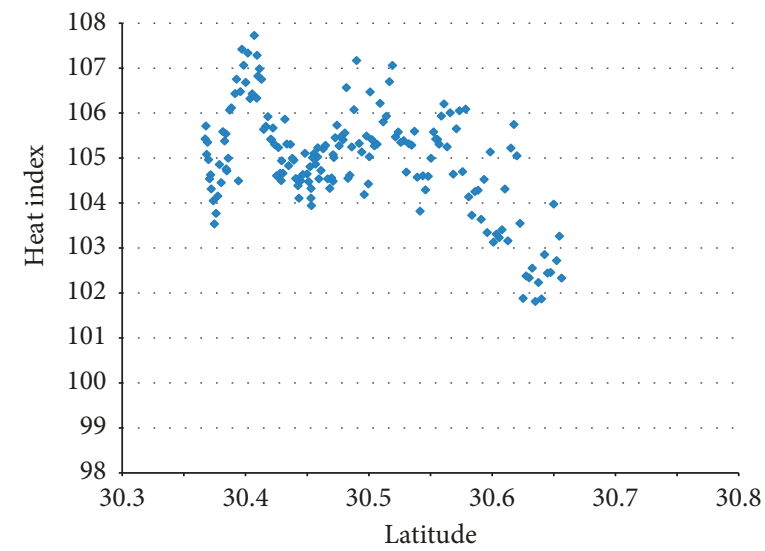

(c)

FIGURE 13: Space series of potential temperature and virtual potential temperature (K) from 10 August 2015. (a) Northbound GulfportSaucier from 1617 to 1651 UTC (1117-1151 CDT); southbound Saucier-Gulfport from 1833 to 1908 UTC (1333-1408 CDT). (b) Southbound Saucier-Biloxi from 1651 to 1717 UTC (1151-1217 CDT); northbound Biloxi-Saucier from 1805 to 1833 UTC (1305-1333 CDT). (c) NWS heat index from southbound Saucier-Gulfport 1833-1908 UTC (1333-1408 CDT).

geographically locked to the vicinity of the coastline regardless of northward progression of other features.

A limited view of longitudinal variations of passive seabreeze characteristics is shown by a counterclockwise loop that was made on the east side of Gulfport. Changes in $\theta_{e}$ occur at similar distance from the coast along US 49 and state route 605 , though the pattern along 605 is complicated by the presence of multiple smaller water bodies (Figure 18). Human comfort impacts of thermodynamic variations from the sea breeze are summarized by the latitudinal variations of NWS heat index [39] from Saucier to Gulfport (Figure 13c), showing that the most dangerous heat stress conditions exist just at the north edge of the SBF transition zone. Maxima of heat index are closely tied to lack of cloud cover as indicated by the solar radiation data (Figure 14). This is a potentially significant societal impact for coastal communities that has not previously been considered at these scales. To demonstrate the intense gradients of surface temperature that drive sensible heat fluxes at the coastline itself, spot measurements of infrared surface temperature were made at the Biloxi beach around 1730 UTC (1230 CDT). Over a distance of tens of meters, the surface temperature went from $34 \mathrm{C}$ in the water to $35.5 \mathrm{C}$ in wet sand to $41-46 \mathrm{C}$ over dry sand and $52 \mathrm{C}$ on concrete.

\section{Advection Calculations}

Using the southerly wind components from KGPT and KBIX applied over the linearly regressed potential temperature gradient between the coast and SBF yields advective cooling rates ranging from -1.5 to $-4.5 \mathrm{~K} / \mathrm{hr}$. By consideration of local temperature tendencies at KGPT and KBIX (nearly zero), the implied diabatic (differential) heating rates would be 1.0 to $4.5 \mathrm{~K} / \mathrm{hr}$. However, the generally very limited inland penetration during the cases implies that the air flow would in most cases take well under one hour to transit from the coast to the SBF. Using hourly temperature changes at KHBG (north of the SBF) as a guide to the intensity of diurnal heating in the absence of advection, it can be estimated that around $1 \mathrm{~K} / \mathrm{hr}$ is due to radiative heating and the remainder is associated primarily with intense turbulent sensible heat flux from the radiatively heated land surface. In 


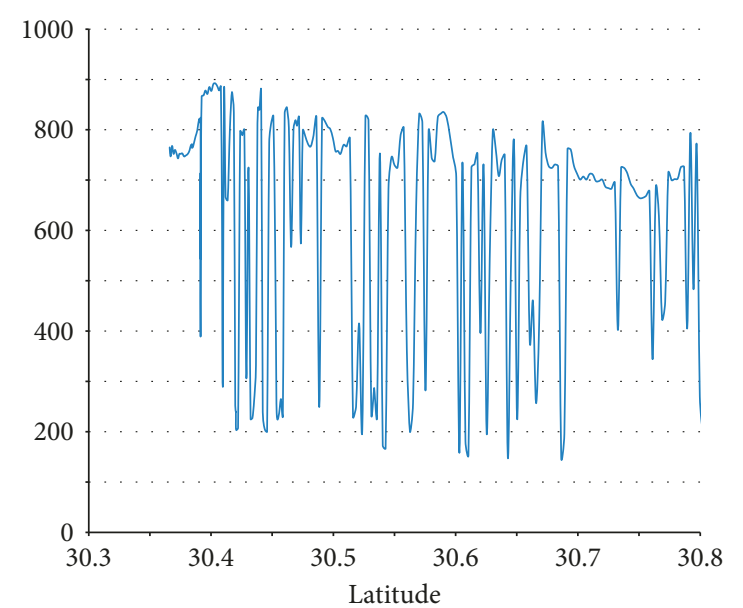

(a)

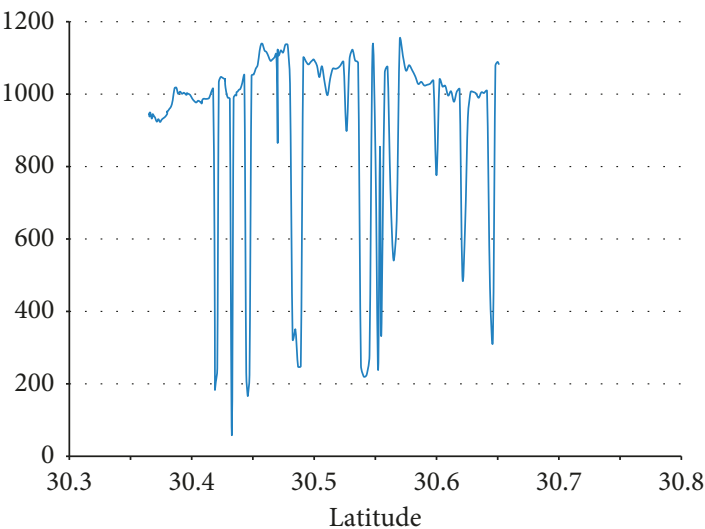

(b)

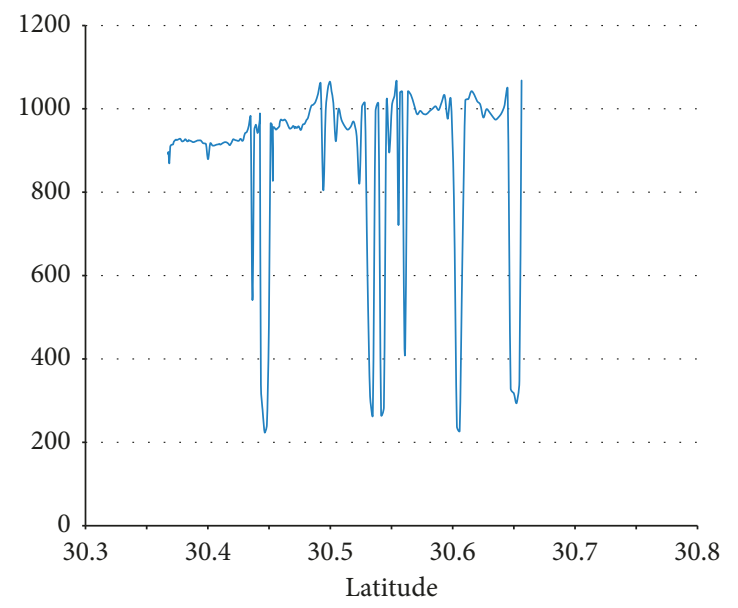

(c)

FIGURE 14: Space series of incoming solar radiation $\left(\mathrm{W} / \mathrm{m}^{-2}\right.$ ) from 10 August 2015. (a) Southbound Wiggins-Gulfport from 1435 to 1527 UTC (0935-1027 CDT). (b) Northbound Gulfport-Saucier from 1617 to 1651 UTC (1117-1151 CDT). (c) Southbound Saucier-Gulfport from 1833 to 1908 UTC (1333-1408 CDT).

actuality, it is likely that the southerly wind component would decrease to nearly zero at the SBF with a proportional decrease in advection.

\section{Conclusions}

High spatial/temporal resolution transects were used along with complementary conventional surface observations, NEXRAD radar reflectivity data, and visible satellite imagery to determine the thermal and moisture structure of the seabreeze front (SBF) along the Mississippi coast during August 2014 and 2015. Results show a 1-2 g/kg increase in mixing ratio across the SBF zone over scales as small as $1 \mathrm{~km}$. Except before 1500 UTC (1000 CDT) (on 10 August 2015), temperatures were always cooler at the coast than inland. However, strong solar insolation may cause temperatures to temporarily rise in the transitional zone near the SBF, resulting in complex small-scale patterns in which the leading edge of marine influence may appear at different distances for temperature, moisture, and clouds. This result is at variance with other diagnostic studies which have not had access to such small-scale measurements at the surface. A conceptual description of such multiparameter microscale SBF variations for the 10 August 2015 case has been proposed.

The largest SBF thermal contrasts observed (as opposed to the broader scale thermal gradient) were on the order of $2.5 \mathrm{C}$, comparable to cases reported by Atkins and Wakimoto [10] from Florida. Some thermal and moisture variations within the marine air mass also appear to be related to the influence of Biloxi Bay and other small coastal water bodies. When radar fine lines were observed by the nearby radars, they agreed very well with thermodynamic measurements of the SBF position. The farthest inland penetration of the SBF during mobile data collection was about $25 \mathrm{~km}$.

Satellite imagery did not show evidence of welldeveloped horizontal convective rolls within the inland air mass. In agreement with aircraft measurements of (relatively strong) sea breezes in Australia [6] and surface 


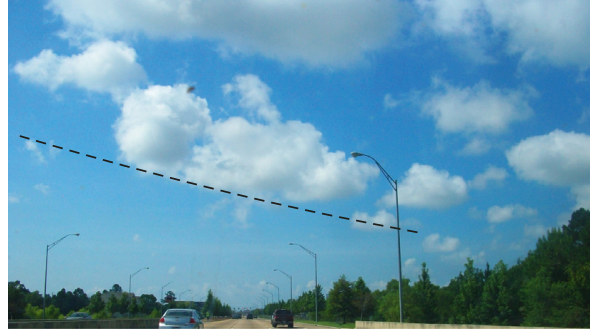

(a)

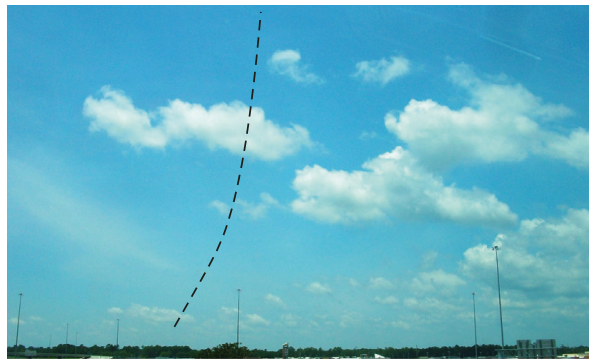

(c)

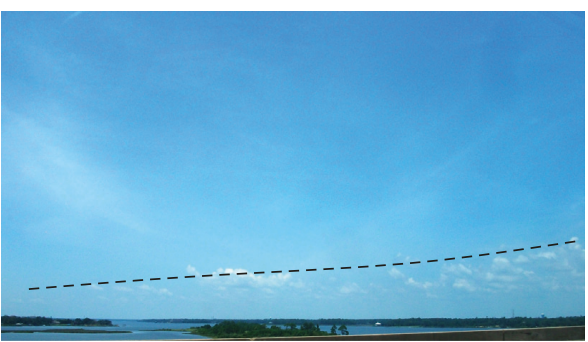

(b)

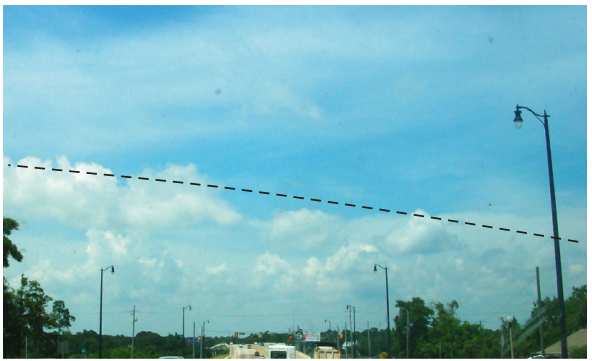

(d)

FIGURE 15: Surface view of cloud development on 10 August 2015. (a) Looking south on US 49 near SBF in Gulfport around 1520 UTC (1020 CDT). (b) View west from Biloxi Back Bay bridge (northbound) around 1808 UTC (1308 CDT). (c) View west of irregular cloud edge near D'Iberville (northbound) around 1811 UTC (1311 CDT). (d) Looking north from 30.4 N (just south of Bayou Bernard) around 1933 UTC (1433 CDT). Dashed line indicates approximate southern boundary to widespread convective clouds.

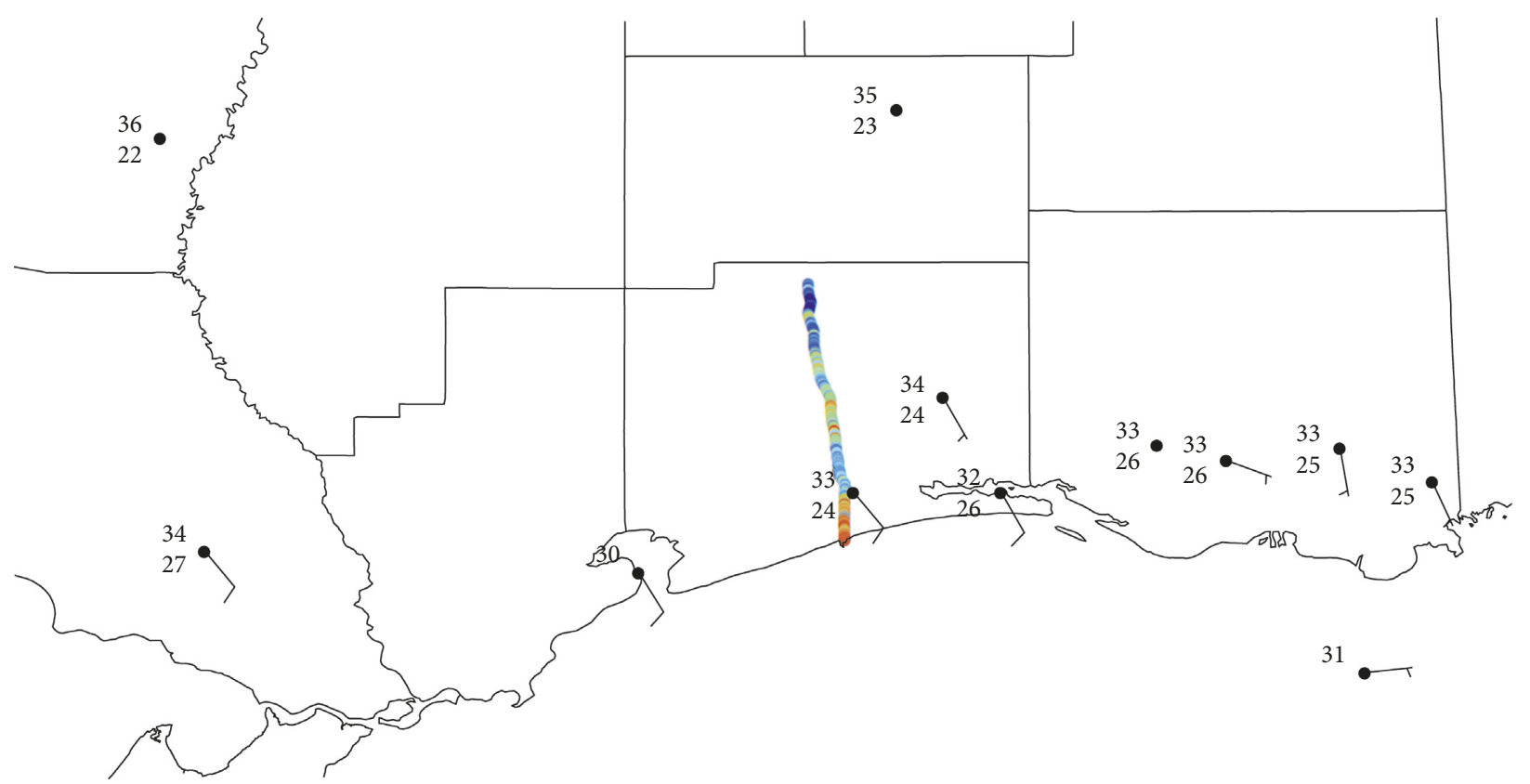

(a)

Figure 16: Continued. 


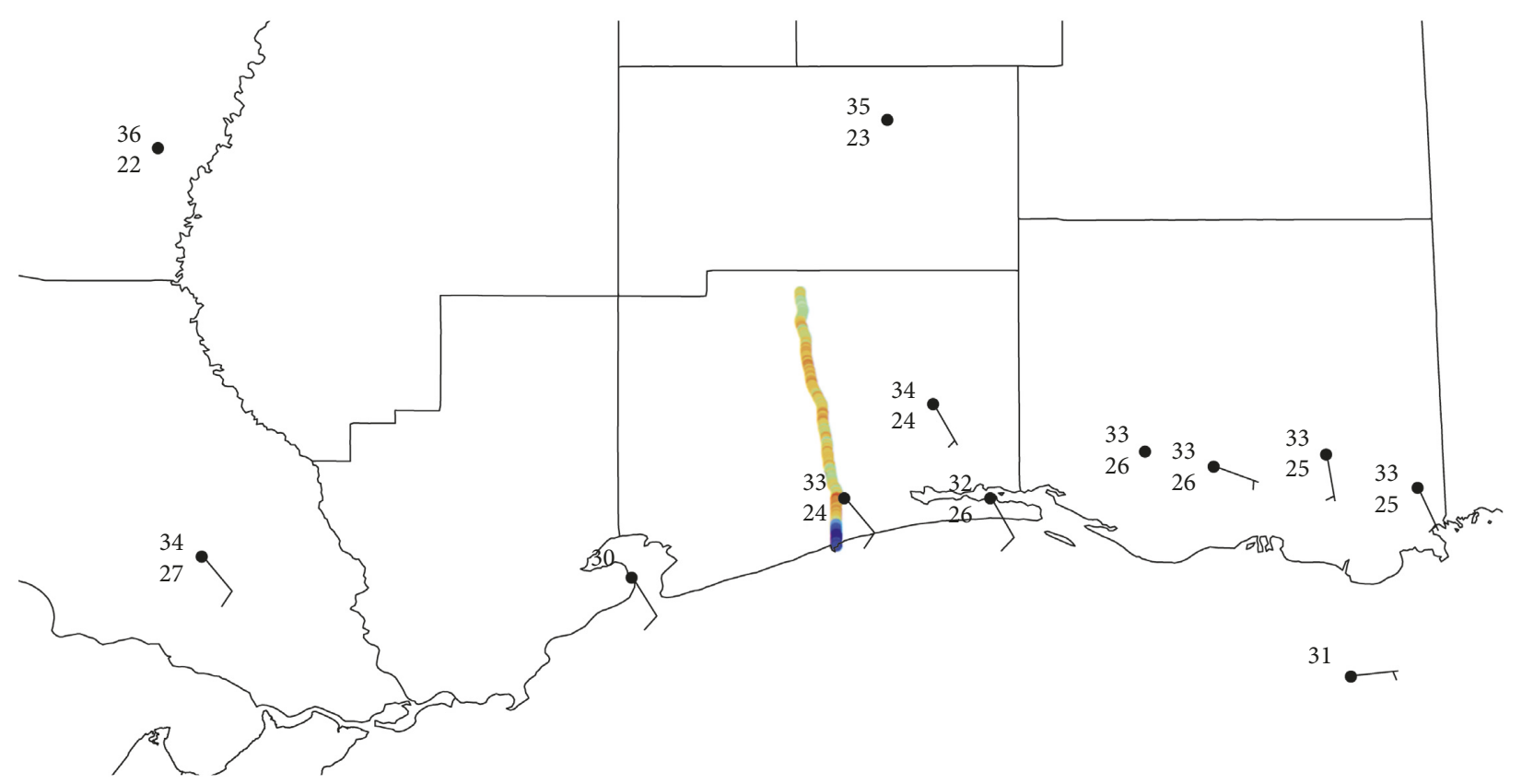

(b)

Figure 16: Map views of 10 August 2015 transect data (southbound Saucier-Gulfport) in relation to 1900 UTC (1400 CDT) station observations. (a) Mixing ratio. (b) Virtual potential temperature (station model as in Figure 6).

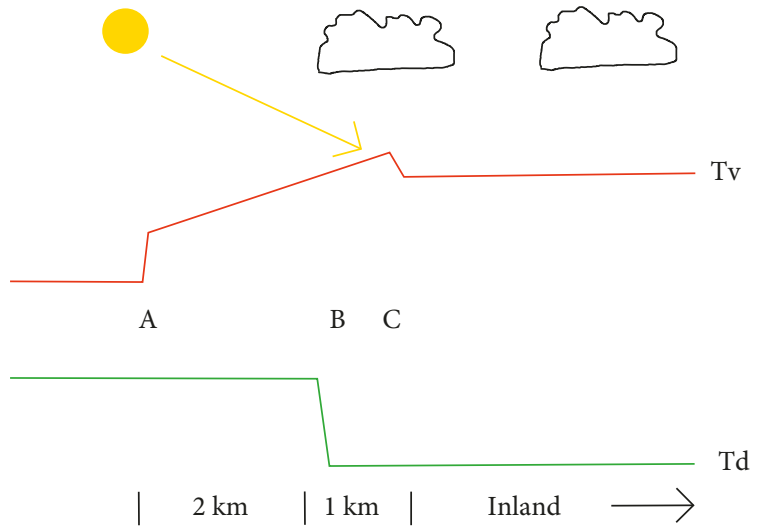

FIGURE 17: Conceptual schematic summarizing detailed structure of observed passive sea breeze, as described in text.

mobile transects of Canadian lake breezes [13], moisture variables, in general, seem to be better determinants of the SBF position than temperature. In contrast, observations of Lapworth [40] in England indicated that thermal contrasts were more pronounced than water vapor across the SBF. It should be noted that afternoon temperatures in the current cases were about $10 \mathrm{C}$ higher and mixing ratios approximately double compared to these other studies. Locally heightened values of NWS Heat Index due to elevated humidity in the marine air have also been identified using the mobile data.

This study was carried out in late summer, when land/sea contrasts are expected to be relatively weak due to warm seasurface temperatures. A diagnostic study over the same region during late spring or early summer might be expected to exhibit stronger solenoidal forcing of sea-breeze circulations. Some preliminary modeling investigations of the role of water temperatures for lake breezes were reported by Arritt [41] and for sea breezes by Kawai et al. [42] and Sweeney et al. [43]. It is suggested that additional microscale diagnostic investigations of sea-breeze thermodynamic structure using mobile observing platforms should be pursued for a variety of geographic and synoptic conditions, in particular with regard to static stability, available moisture supply, land surface character, and topography. The survey by Crosman and Horel [44] has discussed a wide variety of sea-breeze modeling studies. However, observational knowledge of the range of sea-breeze behavior has remained relatively limited, particularly with regard to the smaller scale thermodynamic variations revealed by mobile sampling (either surface or airborne). Sea-breeze modeling studies focused on the northern Gulf of Mexico coast have focused mainly on kinematic and precipitation impacts of the sea-breeze system $[16,17]$. The classic portrayal of a sea breeze occurs most consistently under undisturbed warm conditions at low latitude [45], with the later stages often being confused by interaction with deep moist convection. However, there are other circumstances and forcing mechanisms that may contribute to coastal air mass contrasts, such as coastal fog, topographically trapped stable layers, rain-cooled boundary layers, and marine influences on large-scale cold air masses. In some locales, these processes may occur both in concert with sea-breeze mechanisms and in the absence of a sea breeze. Caution is therefore warranted that not all coastal temperature contrasts are necessarily linked to the specific solenoidal mechanisms implied by the conceptual model of a "sea-breeze system". 


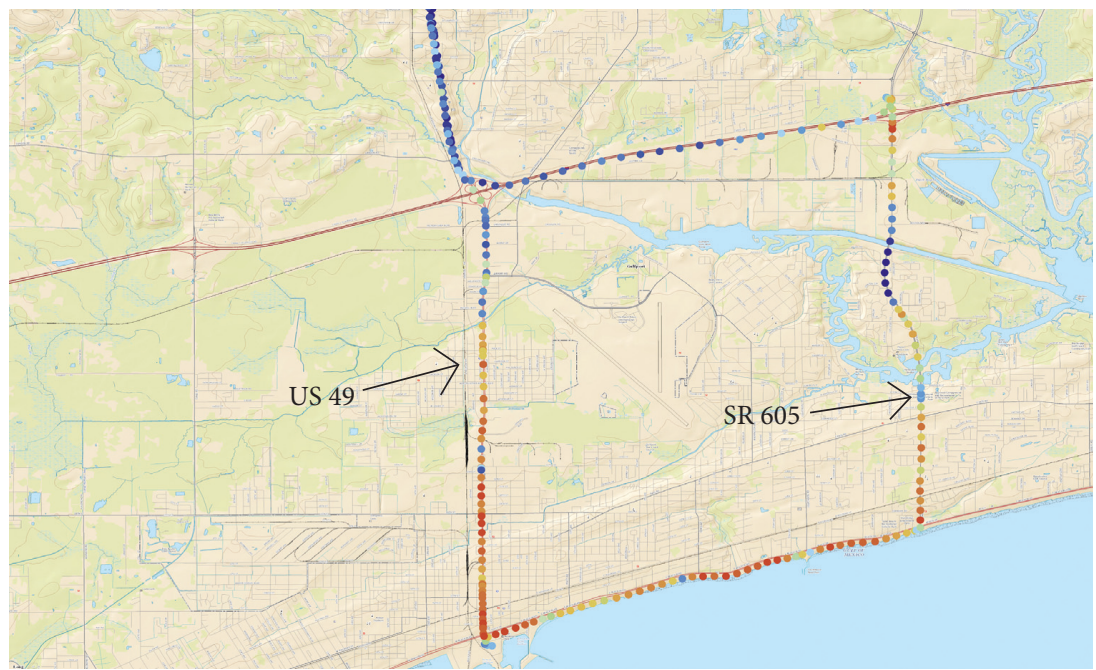

Figure 18: Virtual potential temperature in Gulfport area on 10 August 2015 (collected counterclockwise). Colorized by quantiles for south and northbound separately to emphasize patterns.

\section{Abbreviation}

AGL: Above Ground Level

ASOS: $\quad$ Automated Surface Observing System

AWOS: Automated Weather Observing System

GIS: $\quad$ Geographic Information System

GOES: Geostationary Operational Environmental Satellite

GPS: $\quad$ Geographic Positioning System

MODIS: Moderate Resolution Imaging Spectroradiometer

MS Mississippi Division of Marine Resources

DMR:

NDBC: National Data Buoy Center

NWS: National Weather Service

PAM: $\quad$ Portable Automated Mesonet

RAWS: Remote Automated Weather Station

SBF: sea-breeze front

SCAN: $\quad$ Soil Climate Analysis Network.

\section{Data Availability}

Archivals of surface station data are available for ASOS/AWOS from https://mesonet.agron.iastate. edu/ASOS; for RAWS from http://mesowest.utah.edu; for SCAN from https://www.wcc.nrcs.usda.gov/scan/; and for NDBC from https://www.ndbc.noaa.gov. Satellite imagery from GOES and MODIS are available from https://www. class.ncdc.noaa.gov and NEXRAD reflectivity data from https://www.ncdc.noaa.gov/data-access/radar-data. Mobile data collected for the study are available upon request from the corresponding author (Loren.D.White@jsums.edu).

\section{Conflicts of Interest}

The authors declare that there are no conflicts of interest regarding the publication of this paper.

\section{Acknowledgments}

Data analysis and manuscript preparation were facilitated by White's sabbatical visit hosted by the University of Missouri School of Natural Resources. The manuscript was improved particularly by discussions with Patrick Market. Kristina Broussard generously shared data from mesonet stations of the Mississippi Division of Marine Resources. This study was supported by the NOAA Educational Partnership Program, U.S. Dept. of Commerce (NA11SEC4810003, NA17AE1623) and by the U.S. National Science Foundation (1644888).

\section{References}

[1] B. W. Atkinson, Meso-Scale Atmospheric Circulations, Academic Press, New York, NY, USA, 1981.

[2] S. T. K. Miller, B. D. Keim, R. W. Talbot, and H. Mao, "Sea breeze: structure, forecasting, and impacts," Reviews in Geophysics, vol. 41, no. 3, 2003.

[3] J. C. Fankhauser, N. A. Crook, J. Tuttle, L. J. Miller, and C. G. Wade, "Initiation of deep convection along boundary layer convergence lines in a semitropical environment," Monthly Weather Review, vol. 123, no. 2, pp. 291-313, 1995.

[4] J. E. Simpson, D. A. Mansfield, and J. R. Milford, "Inland penetration of sea-breeze fronts," Quarterly Journal of the Royal Meteorological Society, vol. 103, no. 435, pp. 47-76, 1977.

[5] R. Wood, I. M. Stromberg, and P. R. Jonas, "Aircraft observations of sea-breeze frontal structure," Quarterly Journal of the Royal Meteorological Society, vol. 125, no. 558, pp. 1959-1995, 1999.

[6] K. Stephan, H. Kraus, C. M. Ewenz, and J. M. Hacker, "Seabreeze front variations in space and time," Meteorology and Atmospheric Physics, vol. 70, no. 1-2, pp. 81-95, 1999.

[7] D. M. L. Sills, J. R. Brook, I. Levy, P. A. Makar, J. Zhang, and P. A. Taylor, "Lake breezes in the southern Great Lakes region and their influence during BAQS-Met 2007," Atmospheric Chemistry and Physics, vol. 11, no. 15, pp. 79557973, 2011. 
[8] D. E. Kingsmill, "Convection initiation associated with a seabreeze front, a gust front, and their collision," Monthly Weather Review, vol. 123, no. 10, pp. 2913-2933, 1995.

[9] J. W. Wilson and D. L. Megenhardt, "Thunderstorm initiation, organization, and lifetime associated with Florida boundary layer convergence lines," Monthly Weather Review, vol. 125, no. 7, pp. 1507-1525, 1997.

[10] N. T. Atkins and R. M. Wakimoto, "Influence of the synopticscale flow on sea- breezes observed during CaPE," Monthly Weather Review, vol. 125, no. 9, pp. 2112-2130, 1997.

[11] H. Nakane and Y. Sasano, "Structure of a sea-breeze front revealed by scanning lidar observation," Journal of the Meteorological Society of Japan, vol. 64, no. 5, pp. 787-792, 1986.

[12] N. T. Atkins, R. M. Wakimoto, and T. M. Weckwerth, "Observations of the sea breeze front during CaPE: Part II. Dual-Doppler and aircraft analysis," Monthly Weather Review, vol. 123, no. 4, pp. 944-969, 1995.

[13] M. Curry, J. Hanesiak, S. Kehler, D. M. L. Sills, and N. M. Taylor, "Ground-based observations of the thermodynamic and kinematic properties of lake-breeze fronts in southern Manitoba, Canada," Boundary-Layer Meteorology, vol. 163, no. 1, pp. 143-159, 2016.

[14] J. Horel, E. Crosman, A. Jacques et al., "Influence of the Great Salt Lake on summer air quality over nearby urban areas," Atmospheric Science Letters, vol. 17, no. 9, pp. 480-486, 2016.

[15] J. M. Maldonado Jaime, "Defining environmental characteristics of sea breezes along the US Gulf Coast," M.S. thesis, Mississippi State University, Starkville, MS, USA, 2014.

[16] D. Lu, L. White, R. S. Reddy, P. J. Croft, and J. M. Medlin, "Numerical simulation of sea and bay breezes in a weak shear environment," Meteorology and Atmospheric Physics, vol. 94, no. 1-4, pp. 153-165, 2006.

[17] V. S. Challa, J. Indracanti, M. K. Rabarison et al., "A simulation study of mesoscale coastal circulations in Mississippi Gulf coast," Atmospheric Research, vol. 91, no. 1, pp. 9-25, 2009.

[18] A. Yerramilli, V. S. Challa, J. Indracanti et al., "Some observational and modeling studies of the atmospheric boundary layer at Mississippi Gulf Coast for air pollution dispersion assessment," International Journal of Environmental Research in Public Health, vol. 5, no. 5, pp. 484-497, 2008.

[19] J. R. Smith, H. E. Fuelberg, and A. I. Watson, "Warm season lightning distributions over the northern Gulf of Mexico coast and their relation to synoptic-scale and mesoscale environments," Weather and Forecasting, vol. 20, no. 4, pp. 415-438, 2005.

[20] C. M. Hill, P. J. Fitzpatrick, J. H. Corbin, Y. H. Lau, and S. K. Bhate, "Summertime precipitation regimes associated with the sea breeze and land breeze in southern Mississippi and eastern Louisiana," Weather and Forecasting, vol. 25, no. 6, pp. 1755-1779, 2010.

[21] L. D. White, "Mobile observations of a quasi-frontal transient moisture boundary in the Deep South," Weather and Forecasting, vol. 29, no. 6, pp. 1356-1373, 2014.

[22] P. S. Skinner, C. C. Weiss, Y. P. Richardson, and P. M. Markowski, "Intercomparison between mobile and stationary surface observing platforms in VORTEX2," in Proceedings of 25th AMS Conference on Severe Local Storms, Denver, CO, USA, August 2010, http://ams.confex.com/ams/ pdfpapers/176245.pdf.

[23] P. S. Skinner, C. C. Weiss, J. L. Schroeder, L. J. Wicker, and M. I. Biggerstaff, "Observations of the surface boundary structure within the 23 May 2007 Perryton, Texas, supercell,"
Monthly Weather Review, vol. 139, no. 12, pp. 3730-3749, 2011.

[24] K. Häb, B. L. Ruddell, and A. Middel, "Sensor lag correction for mobile urban microclimate measurements," Urban Climate, vol. 14, pp. 622-635, 2015.

[25] J. M. Straka, E. N. Rasmussen, and S. E. Fredrickson, "A mobile mesonet for finescale meteorological observations," Journal of Atmospheric and Oceanic Technology, vol. 13, no. 5, pp. 921-936, 1996.

[26] S. M. Waugh, "The "U-Tube": an improved aspirated temperature system for mobile meteorological observations, especially in severe weather," M.S. thesis, University of Oklahoma, Norman, OK, USA, 2012.

[27] J. R. Brook, P. A. Makar, D. M. L. Sills, K. L. Hayden, and R. McLaren, "Exploring the nature of air quality over southwestern Ontario: main findings from the Border Air Quality and Meteorology Study," Atmospheric Chemistry and Physics, vol. 13, no. 20, pp. 10461-10482, 2013.

[28] J. E. Simpson, "Aerial and radar observations of some seabreeze fronts," Weather, vol. 22, no. 8, pp. 306-317, 1967.

[29] J. W. Wilson and W. E. Schreiber, "Initiation of convective storms at radar-observed boundary-layer convergence lines," Monthly Weather Review, vol. 114, no. 12, pp. 2516-2536, 1986.

[30] J. W. Wilson, T. M. Weckwerth, J. Vivekanandan, R. M. Wakimoto, and R. W. Russell, "Boundary layer clear-air radar echoes: origin of echoes and accuracy of derived winds," Journal of Atmospheric and Oceanic Technology, vol. 11, no. 5, pp. 1184-1206, 1994.

[31] R. M. Wakimoto and N. T. Atkins, "Observations of the seabreeze front during CaPE. Part I: Single-Doppler, satellite, and cloud photogrammetry analysis," Monthly Weather Review, vol. 122, no. 6, pp. 1092-1114, 1994.

[32] N. F. Laird, D. A. R. Kristovich, R. M. Rauber, H. T. Ochs, and L. J. Miller, "The Cape Canaveral sea and river breezes: kinematic structure and convective initiation," Monthly Weather Review, vol. 123, no. 10, pp. 2942-2956, 1995.

[33] D. D. Reible, J. E. Simpson, and P. F. Linden, "The sea breeze and gravity-current frontogenesis," Quarterly Journal of the Royal Meteorological Society, vol. 119, no. 509, pp. 1-16, 1993.

[34] K. B. Moffett, A. Wolf, J. A. Berry, and S. M. Gorelick, "Salt marsh-atmosphere exchange of energy, water vapor, and carbon dioxide: effects of tidal flooding and biophysical controls," Water Resources Research, vol. 46, no. 10, 2010.

[35] D. Djuric, Weather Analysis, Prentice-Hall, Upper Saddle River, NJ, USA, 1994.

[36] P. Alpert, B. Getenio, and R. Zak-Rosentahl, “One-level modeling for diagnosing surface winds over complex terrain. Part II: applicability to short-range forecasting," Monthly Weather Review, vol. 116, no. 10, pp. 2047-2061, 1988.

[37] P. Alpert and M. Rabinovitch-Hadar, "Pre- and post-seabreeze frontal lines-A meso- $\gamma$-scale analysis over south Israel," Journal of the Atmospheric Sciences, vol. 60, no. 24, pp. 2994-3008, 2003.

[38] R. M. Banta, "Sea breezes shallow and deep on the California coast," Monthly Weather Review, vol. 123, no. 12, pp. 36143622, 1995.

[39] L. P. Rothfusz, The Heat Index "Equation" (or, More Than You Ever Wanted to Know About Heat Index), National Weather Service Technical Attachment SR 90-23, Silver Spring, MD, USA, 1990.

[40] A. Lapworth, "Observations of atmospheric density currents using a tethered balloon borne turbulence probe system," 
Quarterly Journal of the Royal Meteorological Society, vol. 126, no. 569, pp. 2811-2850, 2000.

[41] R. W. Arritt, "The effect of water surface temperature on lake breezes and thermal internal boundary layers," BoundaryLayer Meteorology, vol. 40, no. 1-2, pp. 101-125, 1987.

[42] Y. Kawai, K. Otsuka, and H. Kawamura, "Study on diurnal sea surface warming and a local atmospheric circulation over Mutsu Bay," Journal of the Meteorological Society of Japan, vol. 84, no. 4, pp. 725-744, 2006.

[43] J. K. Sweeney, J. M. Chagnon, and S. L. Gray, "A case study of sea breeze blocking regulated by sea surface temperature along the English south coast," Atmospheric Chemistry and Physics, vol. 14, no. 9, pp. 4409-4418, 2014.

[44] E. T. Crosman and J. D. Horel, "Sea and lake breezes: a review of numerical studies," Boundary-Layer Meteorology, vol. 137, no. 1, pp. 1-29, 2010.

[45] S. T. Gille, S. G. L. Smith, and N. M. Statom, "Global observations of the land breeze," Geophysical Research Letters, vol. 32, no. 5, 2005. 

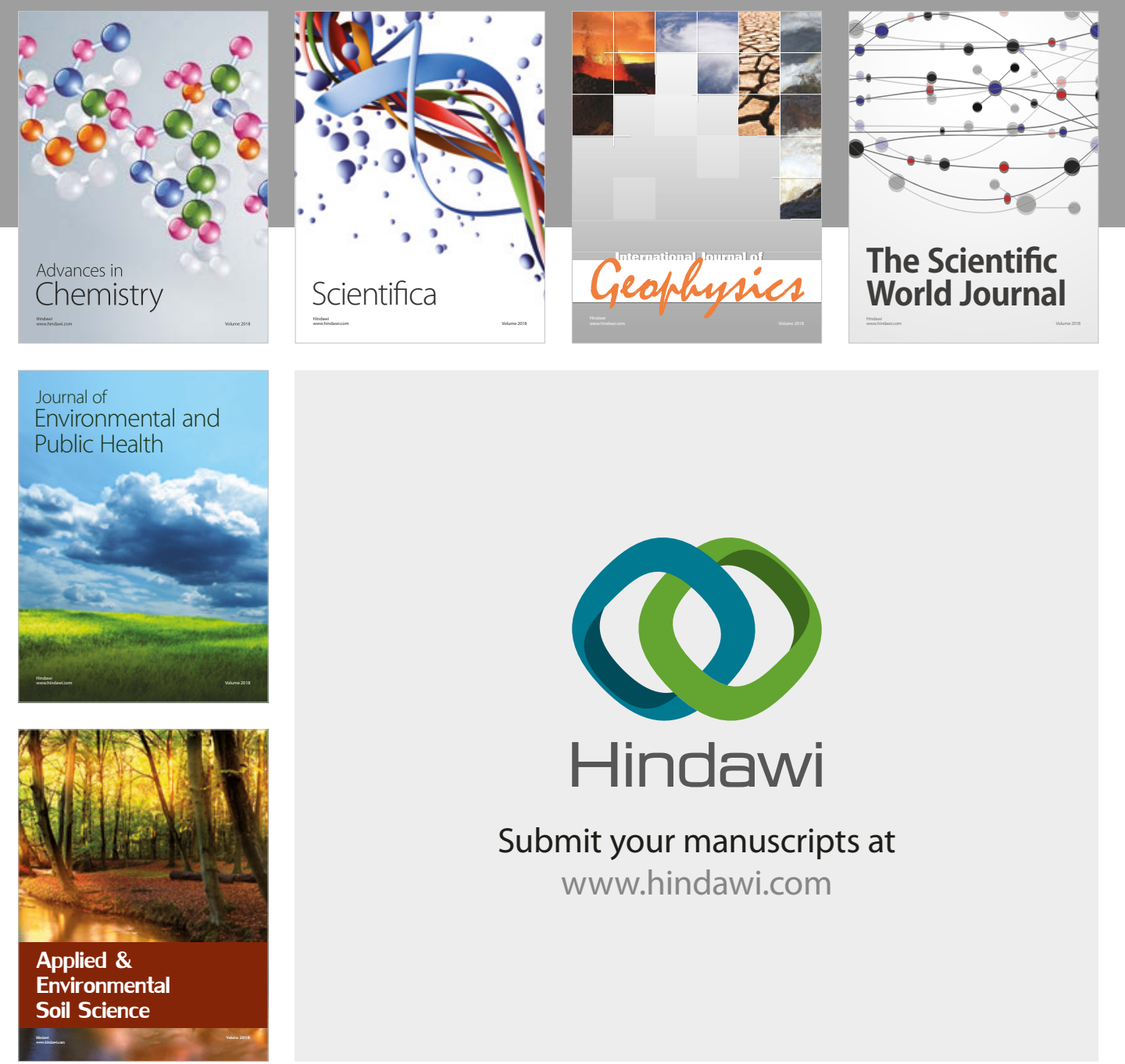

The Scientific

\section{World Journal}
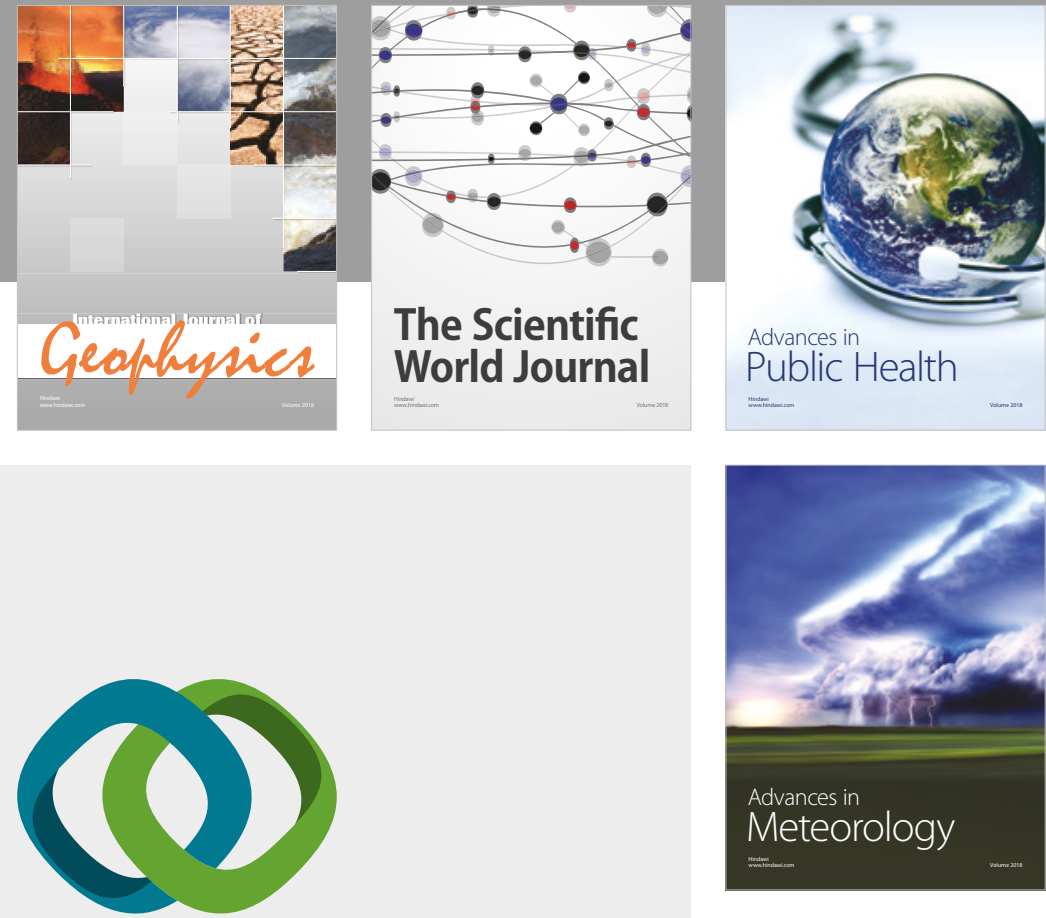

Advan

Public Health

\section{Hindawi}

Submit your manuscripts at

www.hindawi.com
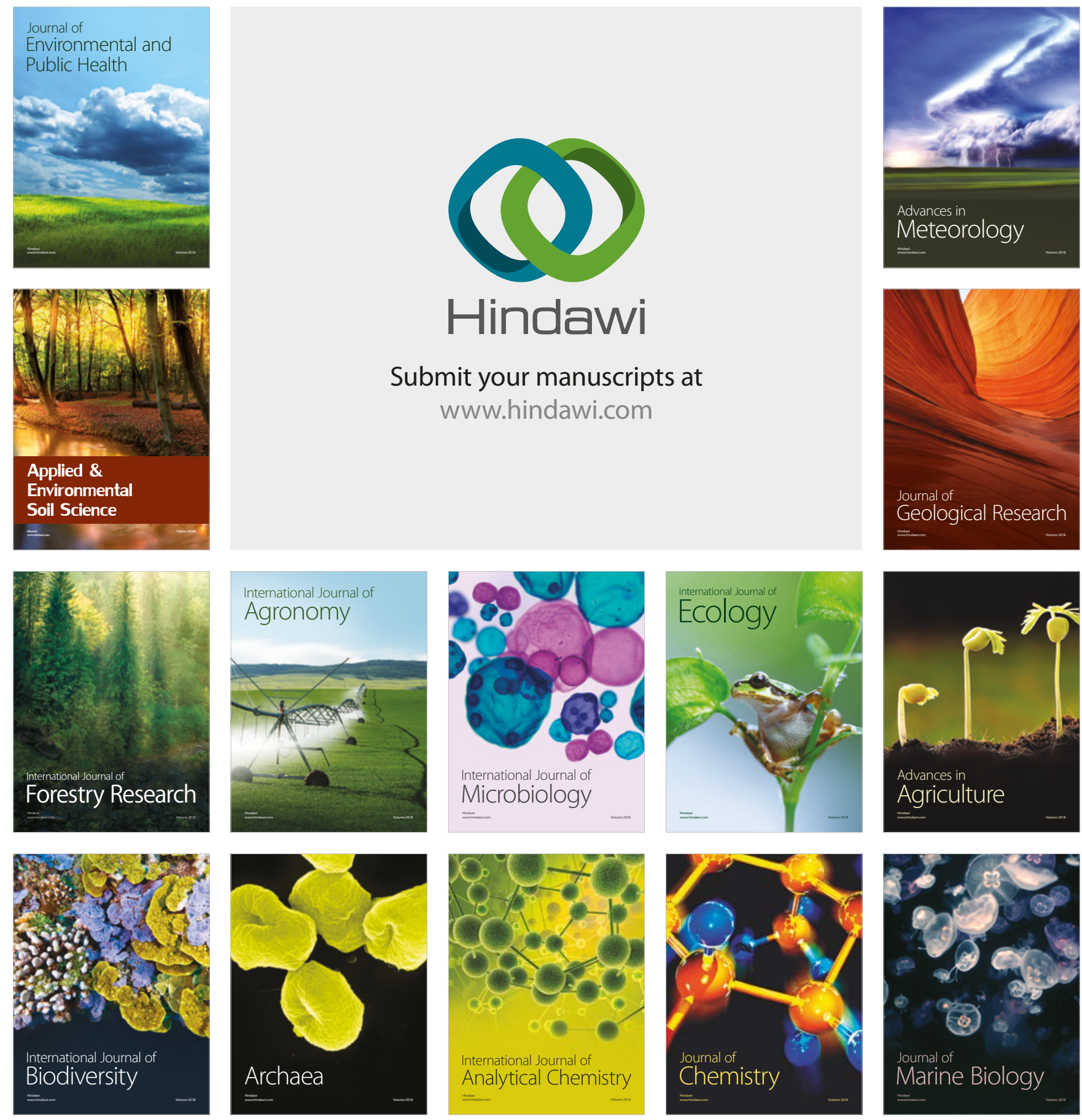